\title{
Striatal Dopamine Modulates Basal Ganglia Output and Regulates Social Context-Dependent Behavioral Variability through $\mathrm{D}_{1}$ Receptors
}

\author{
Arthur Leblois, ${ }^{1}$ Benjamin J. Wendel, ${ }^{1}$ and David J. Perkel ${ }^{1,2}$ \\ Departments of ${ }^{1}$ Otolaryngology and ${ }^{2}$ Biology, University of Washington, Seattle, Washington 98195
}

\begin{abstract}
Cortico-basal ganglia (BG) circuits are thought to promote the acquisition of motor skills through reinforcement learning. In songbirds, a specialized portion of the $B G$ is responsible for song learning and plasticity. This circuit generates song variability that underlies vocal experimentation in young birds and modulates song variability depending on the social context in adult birds. When male birds sing in the presence of a female, a social context associated with decreased BG-induced song variability, the extracellular dopamine (DA) level is increased in the avian BG nucleus Area X. These results suggest that DA could trigger song variability changes through its action in Area $\mathrm{X}$. Consistent with this hypothesis, we report that DA delivered to Area $\mathrm{X}$ weakens the output signal of the avian cortico-BG circuit. Acting through $\mathrm{D}_{1}$ receptors, DA reduced responses in Area X to song playback and to electrical stimulation of its afferent cortical nucleus HVC (used as a proper name). Specifically, DA reduced the response to direct excitatory input and decreased firing variability in Area $\mathrm{X}$ pallidal neurons, which provide the output to the thalamus. As a consequence, DA delivery in Area X also decreased responses to song playback in the cortical output nucleus of the BG loop, the lateral magnocellular nucleus of the anterior nidopallium. Further, interfering with $\mathrm{D}_{1}$ receptor transmission in Area $X$ abolished social context-related changes in song variability. In conclusion, we propose that $D A$ acts on $D_{1}$ receptors in Area $\mathrm{X}$ to modulate the $\mathrm{BG}$ output signal and trigger changes in song variability.
\end{abstract}

\section{Introduction}

Cortico-basal ganglia (BG) circuits are thought to promote motor skill acquisition through reinforcement learning (Hikosaka et al., 2002; Graybiel, 2005). During reinforcement learning, individuals first explore their environment. Reinforcers shape this variable behavior until it converges on an optimum for a particular context. Thereby, repetition of a successful behavior (exploitation) replaces exploration (Sutton and Barto, 1990; Ishii et al., 2002). It remains unclear which neural circuits allow the individual to switch from variable behavior underlying exploration to highly stereotyped behavior during exploitation and how those circuits mediate the switch. However, changes in neural activity in the BG have been interpreted as representing the neural analog of explore-exploit behavior (Barnes et al., 2005).

Songbirds have a specialized portion of their BG, the anterior forebrain pathway (AFP) (Fig. 1A), which is needed for song learning and plasticity (Nordeen and Nordeen, 1997; Brainard and Doupe, 2002) but not for adult song production (Bottjer et al., 1984; Scharff and Nottebohm, 1991). This circuit generates

Received Dec. 2, 2009; revised Feb. 22, 2010; accepted Feb. $25,2010$.

This work was supported by National Institutes of Health Grants R01MH066128, R03DC009686, and P30DC004661. We are grateful to Max Sizemore, Abigail Person, and Sam Gale for valuable comments on this manuscript.

Correspondence should be addressed to David Perkel, Department of Otolaryngology, University of Washington, 1959 NE Pacific Street, Box 356515, Seattle, WA 98195. E-mail: perkel@u.washington.edu.

A. Lebois' present address: Université Paris 5, UMR CNRS 8119 Laboratoire de Neurophysique et Physiologie, 45 rue des Saints Pères, 75270 Paris Cedex, France.

DOI:10.1523/JNEUROSCI.5974-09.2010

Copyright $\odot 2010$ the authors $\quad 0270-6474 / 10 / 305730-14 \$ 15.00 / 0$ song variability that underlies vocal experimentation in young birds (Ölveczky et al., 2005). In adult birds, the same circuit can modulate song variability depending on the social context (Kao et al., 2005; Kao and Brainard, 2006) or provide an instructive signal to guide adaptive changes in vocal output (Kao et al., 2008; Andalman and Fee, 2009). The neural input triggering changes in BG-driven song variability remains unknown.

In the $B G$, the neuromodulator dopamine (DA) plays a key role in reinforcement learning (Montague et al., 1996). Because DA delivery in the striatum signals reward prediction errors, it may provide a reinforcement signal to the BG (Schultz et al., 1993; Phillips et al., 2003; Wise, 2004). However, recent studies suggest that DA function in motor learning may go beyond such a reinforcement signal (Salamone et al., 2005; Costa, 2007). In particular, the DA system is involved in the regulation of interindividual differences in exploration and exploitation behaviors (Frank et al., 2009). Moreover, DA is also involved beyond motor learning in the representation of social cues in mammals (Wang et al., 1999; Anstrom et al., 2009; Aragona and Wang, 2009).

In songbirds, the song-related BG nucleus Area $\mathrm{X}$ receives dense dopaminergic innervation from the substantia nigra pars compacta (SNc) and ventral tegmental area (VTA) (Lewis et al., 1981; Bottjer, 1993; Gale et al., 2008). Immunocytochemical data suggest that DA plays a social context-dependent role in the regulation of vocal communication (Heimovics and Riters, 2008). In addition, DA level is increased in Area X of male birds when they sing to females (Sasaki et al., 2006), a social context associated with decreased BG-induced song variability (Kao et al., 2005). Moreover, VTA neurons, possibly including dopaminergic neu- 
A

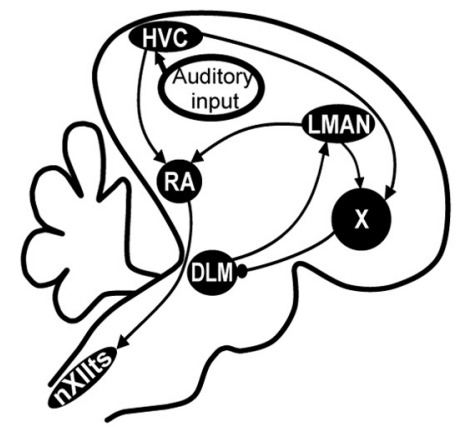

D

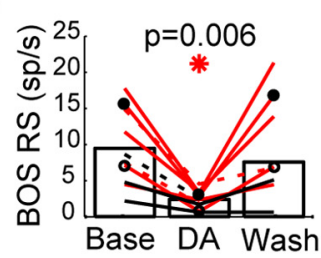

E

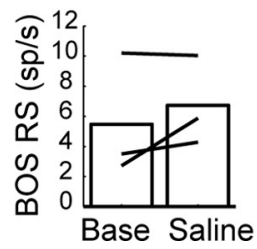

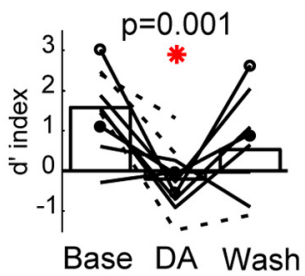

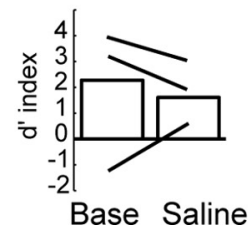

B

- Neuron 1
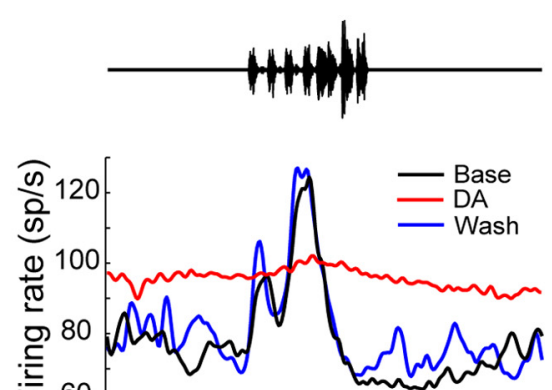

60

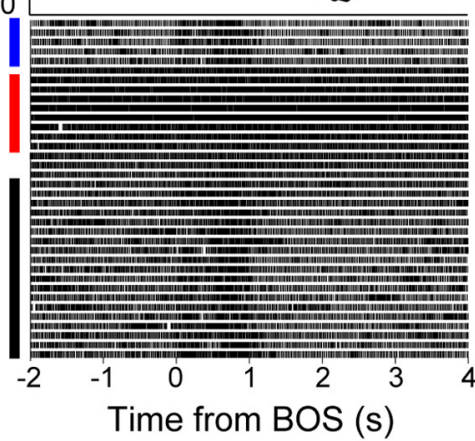

C
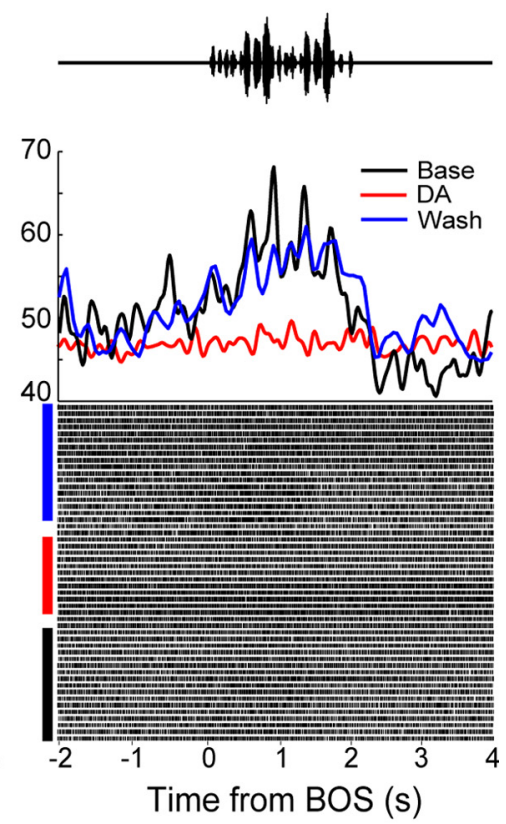

Figure 1. DA suppresses responses to playback of the BOS in Area X output neurons. $A$, Schematic parasagittal representation of the song system. In the present study, neuronal activity was recorded in the AFP nuclei Area X and LMAN. Dorsal is up, anterior is to the right. $\boldsymbol{B}$, Example of a neuron with increased spontaneous activity and decreased song response after DA injection. Top, Oscillogram of song playback. Middle, PSTH around BOS presentation. Bottom, Corresponding raster plot. Black lines, Baseline; red lines, DA; blue lines, washout. C, Example of a neuron in which spontaneous activity was unaffected by DA injection but which also showed decreased song response after DA injection (red trace). PSTH around BOS presentation, with the same conventions as in B. D, Injection ofDA $(n=7)$ or the $D_{1}$-type receptor agonist SKF38393 $(n=3)$ in Area X reduces the response to BOS playback in all neurons. Left, BOS response strength; right, $d^{\prime}$. Solid lines indicate DA injections; dotted lines SKF38393 injections. In the left panel, red lines indicate significant changes in BOS response strength. Filled circles indicate BOS response strength and $d^{\prime}$ values for the neuron shown in $\boldsymbol{A}$, and empty circles indicate values for the neuron shown in $\boldsymbol{B}$. $\boldsymbol{E}$, Vehicle injection did not change BOS response strength (left) or selectivity index ( $\boldsymbol{d}^{\prime}$, right).

rons, show singing-related activity that is modulated by social context (Yanagihara and Hessler, 2006) and DA neurons express Fos after social stimuli (Bharati and Goodson, 2006). These results suggest that DA delivery in Area X could trigger changes in BG-driven song variability. More generally, such a mechanism would allow DA to regulate the balance between exploration and exploitation during and after the acquisition of motor skills.

\section{Materials and Methods}

\section{Animals}

Adult male zebra finches (Taeniopygia guttata) were obtained from a commercial supplier and used in accordance with an animal protocol approved by the University of Washington Institutional Animal Care and Use Committee. Animals were housed under a 14/10 h light/dark cycle with food and water available ad libitum.

\section{Surgical procedures}

In vivo recordings. Each animal was first food deprived for $30 \mathrm{~min}$ and then given three intramuscular injections totaling 5-6.5 ml/kg of $20 \%$ urethane over $1 \mathrm{~h}$. Local anesthetic (1\% lidocaine) was injected under the scalp before the animal was placed in a stereotaxic apparatus with the beak at an angle of $64^{\circ}$ downward from the horizontal. Small craniotomies were made above the midline reference point, the bifurcation of the midsagittal sinus, and above HVC (used as a proper name) and the lateral magnocellular nucleus of the anterior nidopallium (LMAN) or Area X unilaterally. Lidocaine gel was then applied to the incision at $3 \mathrm{~h}$ intervals.

Cannula implantation. We infused drugs in the CNS using a combination of osmotic minipumps and cannulas, as in the study by Meitzen et al. (2007). Animals were anesthetized with $2 \%$ isoflurane and placed in a stereotaxic apparatus with a head angle of $64^{\circ}$. Anesthesia was maintained with $1 \%$ isoflurane for the duration of the surgery. Local anes- thetic ( $1 \%$ lidocaine) was injected under the scalp, and small craniotomies were made above the midline reference point, the bifurcation of the midsagittal sinus, and at $6.5-7 \mathrm{~mm}$ anterior, $1.8 \mathrm{~mm}$ lateral from the reference point. The head angle was then changed to $0^{\circ}$. Two small bent cannulae (Alzet) were lowered to the surface of Area X (2.5-3 $\mathrm{mm}$ deep) and attached to the skull with dental cement. An osmotic minipump (Alzet, length, $17 \mathrm{~mm}$; diameter, $6 \mathrm{~mm}$; filled weight, $0.5 \mathrm{~g}$; model 1002, 14 d delivery) filled with $100 \mu \mathrm{l}$ of drug solution was then connected to the two cannulae with polyvinylchloride tubing and a $\mathrm{Y}$ distributor. The pumps were placed in a custom built backpack strapped to the bird's back using a harness made from surgical dressing. To mount the osmotic pump in the backpack, we used a $0.65 \mathrm{ml}$ plastic microcentrifuge tube (ISC BioExpress) filled with $250 \mu \mathrm{l}$ of sterile saline. We threaded the output tube of the pump through a hole in the cap and inserted the pump snugly into the microcentrifuge tube until the lid snapped into place. We sealed the lid and tube extrusion hole using cyanoacrylate adhesive and Parafilm (Fisher Scientific).

\section{In vivo electrophysiology}

Recordings. Glass pipettes (TW100F-3, World Precision Instruments) were pulled using a micropipette puller (Model P97, Sutter Instrument), and the tips were blunted to impedances of 5-25 M $\Omega$. A ground electrode was placed in the cerebellum posterior to the midline reference point. A concentric stimulation electrode (FHC) was placed in HVC (0 mm rostral, $2.4 \mathrm{~mm}$ lateral to the midline reference point, $0.5 \mathrm{~mm}$ deep). The recording electrode signal was amplified $10 \times$ and low pass filtered at 3 $\mathrm{kHz}$ (Axoclamp2B amplifier, Molecular Devices), amplified further $100 \times$ and high pass filtered at $300 \mathrm{~Hz}$ (model 440, Brownlee Precision). Recordings were monitored using an oscilloscope and an audio monitor. We searched for single-unit neuronal activity in Area X or LMAN using HVC stimulation as a search stimulus. Once a neuron was isolated, the 
electrophysiological signal was sampled at $20 \mathrm{kHz}$ and spike times and raw traces were stored for further analysis (Spike2, Cambridge Electronic Design). Principal components analysis of the spike shapes allowed clear separation from noise and all extracted units obeyed a refractory period of $1 \mathrm{~ms}$. In recordings in Area X, neurons displaying spontaneous firing of $>25$ spikes/s (sp/s) are referred to as pallidal neurons given their similarity with identified Area X pallidal neurons recorded at their terminals in the medial portion of the dorsolateral nucleus of the thalamus (DLM) (Person and Perkel, 2007). Moreover, we have shown in a previous study (Leblois et al., 2009) that $>66 \%$ of these neurons are antidromically activated from DLM. In contrast, Area X pallidal neuron axons recorded in DLM never display firing rates of $<25 \mathrm{sp} / \mathrm{s}$. Hence, Area X neurons displaying a firing rate lower of $<25 \mathrm{sp} / \mathrm{s}$ are hereafter called putative interneurons.

Electrical stimulation. Recordings were performed during HVC microstimulation (monophasic $0.2 \mathrm{~ms}$ single pulses) with various stimulation intensities $(10-2000 \mu \mathrm{A})$. Each pulse of HVC microstimulation saturated the amplifier and occluded spiking activity for $1-2 \mathrm{~ms}$ in the recordings, due to the "overshoot" following saturation. Because the duration of this stimulation artifact was much shorter than the fastest responses recorded, it occluded only spontaneous activity and thus did not alter our analysis of evoked firing. Previous studies have shown that stimulation with a monopolar microelectrode at $200 \mu$ A activates $\sim 50 \%$ of the neurons located in a shell of $0.2 \mathrm{~mm}$ outside radius (Ranck, 1975; Tehovnik et al., 2006). These values should be considered with caution because the current intensity necessary to activate a soma or axon at a given distance depends on a number of other variables such as the size of the cell or its biophysical properties (e.g., cellular excitability or axon myelination). In addition, concentric bipolar electrodes greatly reduce current spread, especially for higher stimulation intensities (Bagshaw and Evans, 1976; Follett and Mann, 1986), and estimates from monopolar electrodes thus provide an imprecise upper bound of the activated volume. The volume of the "activated shell" for $200 \mu \mathrm{A}$ (inside and outside radius: 0.1 and $0.2 \mathrm{~mm}$ ), is $0.029 \mathrm{~mm}^{3}$, and represents $\sim 10 \%$ or less of HVC volume (0.2-0.5 $\mathrm{mm}^{3}$, MacDougall-Shackleton et al., 1998). Therefore, $200 \mu \mathrm{A}$ pulses applied near the center of HVC through concentric bipolar electrodes are expected to activate $<5 \%$ of HVC neurons.

We cannot exclude the possibility that some high amplitude stimulation led to current spread to neighboring structures. However, because of the segregation of the AFP circuit, we believe that occasional activation of neighboring structures does not modify the interpretation of the present data.

Drug injections. All drugs were diluted in a $0.9 \%$ saline solution with $0.5 \%$ dextran-conjugated Alexa-fluor 488 (3000 molecular weight; Invitrogen). The role of DA in Area X was examined using microinjection of DA or related compunds (0.5-2 mm, Tocris Bioscience). Drugs were pressure ejected from glass pipettes (10-20 $\mu \mathrm{m}$ tip diameter) using a Pressure System IIe (Toohey; $50 \mathrm{~ms}$ pulses at 10-16 psi). Injected volumes were 20-100 $\mathrm{nl}$. When the recording and drug injections were made in the same structure, we aimed to place the tip of the injection pipette 200-300 $\mu \mathrm{m}$ from the tip of the recording pipette. We recorded 21 neurons in Area X before, during, and after DA injections in the same nucleus in 10 birds (1-4 neurons per bird). We recorded 17 neurons in LMAN before, during, and after DA injections in Area X in 13 birds (1-3 neurons per bird). When multiple neurons were recorded from the same animal, we waited at least $2 \mathrm{~h}$ between two consecutive DA injections to make sure that DA was washed out.

\section{In vitro electrophysiology}

Preparation of brain slices. Slicing procedures were as described by Farries and Perkel (2000). Briefly, each animal was anesthetized with isoflurane and killed by decapitation. The brain was dissected rapidly into ice-cold, oxygenated artificial CSF (ACSF) containing the following (in mM): 119 $\mathrm{NaCl}, 2.5 \mathrm{KCl}, 1.3 \mathrm{MgSO}_{4}, 2.5 \mathrm{CaCl}_{2}, 1 \mathrm{NaH}_{2} \mathrm{PO}_{4}, 16.2 \mathrm{NaHCO}_{3}, 11$ D-glucose, and 10 HEPES, with osmolarity adjusted to $300 \mathrm{mOsm}$ with sucrose. Coronal brain slices (300-450 $\mu \mathrm{m}$ thick) were prepared using a vibrating microtome (Vibratome), and slices were stored at room temperature submerged in bubbled ACSF in which HEPES was replaced with equiosmolar $\mathrm{NaHCO}_{3}$. All chemicals were obtained from Sigma-Aldrich. All solutions were bubbled with a $95 \% \mathrm{O}_{2}$ and $5 \% \mathrm{CO}_{2}$ mixture.

Electrophysiological recording. After resting for at least $1 \mathrm{~h}$ after sectioning, slices were placed in a recording chamber and superfused with ACSF heated to $28-30^{\circ} \mathrm{C}$. Glass pipettes were pulled to a tip of $<2 \mu \mathrm{m}$ in diameter (Micropipette Puller P-97, Sutter Instrument), filled with $0.9 \%$ saline, and had a resistance of 4-8 $\mathrm{M} \Omega$. Signals were amplified with either an Axoclamp 2B (Molecular Devices) followed by a Brownlee Precision DC amplifier, or with a MultiClamp 700B amplifier (Molecular Devices). Signals were low pass filtered at $3 \mathrm{kHz}$, high pass filtered at 300 $\mathrm{Hz}$, and digitized at $20 \mathrm{kHz}$ with a Digidata 1322A (Molecular Devices) and stored on a personal computer using pClamp 9 (Molecular Devices). A tungsten bipolar stimulating electrode was placed near the boundary of Area $\mathrm{X}$ in a location that distinguishes inputs from HVC versus the LMAN, on the basis of a previous description of innervation patterns (Ding and Perkel, 2003). Recording pipettes were placed near and ventral to the stimulating electrode in most cases. The spatial relationship between the stimulating and recording electrodes in the other axes varied. Once a spontaneously active neuron was located, the recording electrode was approached as close as possible to obtain a signal-to-noise ratio of $>3$. Then, short-latency spiking was evoked by electrical stimulation at $0.1-0.2 \mathrm{~Hz}$.

\section{Anatomy}

Following in vivo recording. At the end of each acute recording experiment, recording sites were labeled by iontophoretic injections of fluorescent dye (5\% Alexa-488- or -568-conjugated $10 \mathrm{kDa}$ dextran amine in $0.01 \mathrm{M}$ phosphate buffer, $\mathrm{pH} 7.4$, ejected by $5 \mu \mathrm{A}$ DC pulses of $7 \mathrm{~s}$ duration, $50 \%$ duty cycle for $5 \mathrm{~min}$ ). Animals were killed by intramuscular injection of sodium pentobarbital (Nembutal) and perfused transcardially with $0.9 \%$ saline followed by $4 \%$ paraformaldehyde as fixative. The brain was then removed, postfixed in $4 \%$ paraformaldehyde for $24 \mathrm{~h}$, and cryoprotected in $30 \%$ sucrose. Sections ( $40 \mu \mathrm{m}$ thick) were then cut in the parasagittal plane on a freezing microtome and processed for histological examination to verify the location of stimulating and recording electrodes and drug injection sites. In addition to gross observation of electrode tracts, the brain slices were visualized using a fluorescence microscope to allow better determination of recording location. A summary of recording locations reconstructed from stereotaxic coordinates and post hoc histological analysis is presented on Figure 2.

Following cannula infusion. At the end of cannulation experiments, animals were killed by overdose of pentobarbital and perfused transcardially with $0.9 \%$ saline followed by $4 \%$ paraformaldehyde. The brain was then removed, postfixed in $4 \%$ paraformaldehyde for $24 \mathrm{~h}$, and cryoprotected in $30 \%$ sucrose. Sections (50 $\mu \mathrm{m}$ thick) were then cut in the parasagittal plane on a freezing microtome, mounted on slides, and stained with cresyl violet. Histological examination showed that the cannula tip was in Area X or $<500 \mu \mathrm{m}$ away from the edge of Area X in all four birds and that any lesion due to cannula placement and drug flow was restricted to a region not exceeding 10\% of the total volume of Area X. A $50 \mu \mathrm{m}$ parasagittal brain section showing the track of the cannula used to infuse drugs in the behaving bird is shown below (see Fig. 10).

\section{Song recordings}

Birds were individually housed in sound isolation chambers (Acoustic Systems) $7 \mathrm{~d}$ before and 20-40 d following the cannula implantation surgery. We continually recorded spontaneous vocalizations using Syrinx software (John Burt, www.syrinxpc.com). In addition, we recorded vocalizations evoked by the presentation of a female by placing a female in the cage for 3-4 min, at intervals of $>20 \mathrm{~min}$. Such presentation was performed $<6$ times a day and for at least $3 \mathrm{~d}$ in each condition.

\section{Data analysis}

Acute recordings. Spike times were analyzed using Matlab software (version 7.5.0.342, R2007b, MathWorks). For each cell, we calculated spontaneous firing rate, interspike interval (ISI) distribution, and peristimulus time histogram (PSTH) of the response to HVC stimulation and/or to song playback. The average firing rate during song playback was calculated. Spontaneous firing rate was calculated during a window of the same duration as the song playback preceding the playback. The differ- 
A

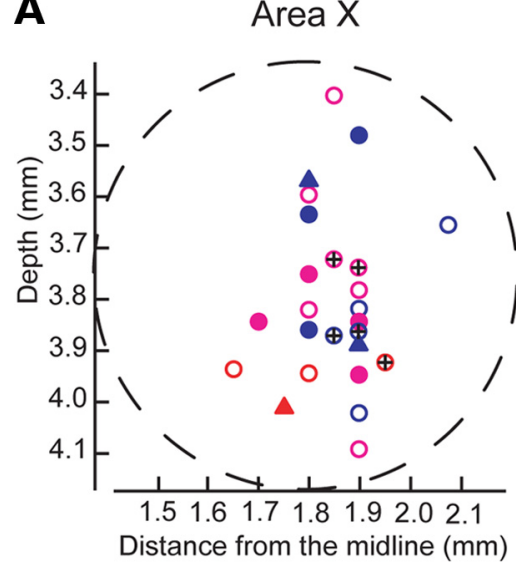

B

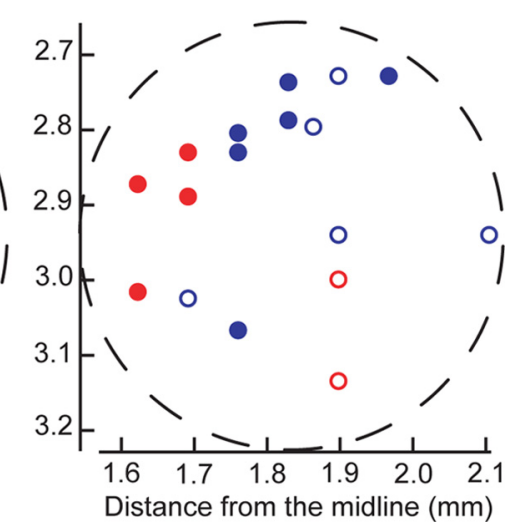

Figure 2. Location of neurons recorded in Area $X$ and LMAN in vivo, reconstructed from stereotaxic coordinates and post hoc histological analysis. Each panel represents the medial-lateral coordinate and the depth of all recording locations in one structure. Anteroposterior coordinates of the recording locations are displayed by color. Each recorded neuron is represented with a symbol that denotes the stimulus presented during the recording, the drug treatment applied, and/or the neuron type. $A$, Location of neurons recorded in Area X. Anteroposterior coordinates: blue, $\leq 3.5$; magenta, 3.5-3.7; red, $\geq 3.7$. Symbols: circles, DA treatment; triangles, SKF38393 treatment; empty symbols, electrical stimulation of HVC; filled symbols, song stimulation and electrical stimulation of HVC. Symbols with a cross denote putative interneurons $(<25 \mathrm{sp} / \mathrm{s})$, while others represent pallidal neurons. $B$, Location of neurons recorded in LMAN. Anteroposterior coordinates: blue, $\leq 3.9 ;$ red, $\geq 3.9$. Empty symbols, Electrical stimulation of HVC; filled symbols, song stimulation.

ence between the firing rate during and before a given song playback was calculated for each trial and averaged across trials to give a mean song response strength (Solis and Doupe, 1997). Song response strength measurements were used to calculate the discriminability statistic $d^{\prime}$, which is used to quantify the selectivity of a neuron for a given stimulus over another (Solis and Doupe, 1997), where the difference between the average song response strength (RS) to two songs was normalized by the square root of the average of the variances of the song response strength $(\sigma)$ measurements for the two songs, as follows:

$$
d_{\mathrm{BOS}-\mathrm{Re} \nu}^{\prime}=\frac{2\left(\mathrm{RS}_{\mathrm{BOS}}-\mathrm{RS}_{\mathrm{Re} \nu}\right)}{\sqrt{\sigma_{\mathrm{BOS}}^{2}+\sigma_{\mathrm{Re} \nu}^{2}}} .
$$

Analyses of responses to HVC stimulation were performed on PSTHs smoothed as follows. For each trial, the firing rate time course was determined with $1 \mathrm{~ms}$ resolution by convolving the spike train with a Gaussian kernel of width $1 \mathrm{~ms}$ (Baker and Gerstein, 2001). The mean and SD of the spontaneous rate were determined over the $100 \mathrm{~ms}$ preceding stimulation. A neuron was considered to display a significant response if at least two consecutive bins of the PSTH were beyond limits defined by the spontaneous mean $\pm 2.5 \mathrm{SD}$. Responses were often made up of several components (especially in Area X pallidal cells), some inhibitory and some excitatory. We defined the beginning of the response component as the time of the first of two consecutive bins of the PSTH in which the firing rate fell outside significance limits; similarly, the end occurred when two consecutive bins fell back within significance limits. Stimulation response strength, similar to the song response strength but calculated over a short time window ( $30 \mathrm{~ms}$ in Area X, $60 \mathrm{~ms}$ in LMAN), was defined as the difference between the average firing rate over the response window following $\mathrm{HVC}$ stimulation, and the average spontaneous firing rate over a window of the same duration preceding HVC stimulation. We defined excitation (or inhibition) relative area as the percentage increase or decrease in number of spikes relative to the average number of spikes, across the population of cells, expected in a response window of spontaneous firing. To this end, the area of the PSTH significantly above (or below) spontaneous firing was divided by the population average spontaneous firing rate. The result was expressed as a percentage of the population average spontaneous firing. For LMAN neurons, Area X putative interneurons and pallidal neurons displaying only excitatory responses, the lowest stimulation current intensity evoking a reliable response (at least one additional spike in each trial) was selected for further analysis. For pallidal neurons displaying some inhibition in response to stimulation, the lowest current intensity evoking an inhibitory component in their response was selected for further analysis.

Song sorting and analysis. Songs were sorted and analyzed using custom Matlab programs. Zebra finch songs are highly stereotyped, making them especially well suited for in-depth analysis. The acoustic structure of song is arranged in a hierarchy, with 5-50 ms vocal units known as syllables strung together in a stereotyped sequence called a motif. Each song consists of one or several motifs, preceded by introductory notes and separated from each other by $<100 \mathrm{~ms}$ of silence. We designed a program to sort motifs and songs from all sound files continuously recorded using the Syrinx software. Briefly, the program detected putative motifs based on peaks in the crosscorrelation between the recorded sound file and a clean preselected motif. Such putative motifs were then sorted based on their spectral similarity with the preselected clean motif, using thresholds set by the experimenter. For motifs for which such analysis did not allow unambiguous distinction, an additional PCA analysis on the spectrograms of putative motifs allowed us to sort motifs from other sounds. This analysis allowed us to successfully sort $>90 \%$ of the motifs sung by a bird on a given day (assessed by comparing hand sorting with the automated sorting by the program).

Song analysis consisted of determining the fundamental frequency of harmonic stacks and the frequency of the lowest harmonic in all subsyllabic elements displaying clear frequency modulation. The latter feature is strongly correlated with fundamental frequency for subsyllabic elements displaying a harmonic stack structure (cf. next paragraph), and can also be calculated for nonharmonic elements. Fundamental frequency was calculated based on peaks in the autocorrelation function, as in the study by Kao and Brainard (2006). The frequency of the lowest harmonic was estimated as follows. For each subsyllabic element considered, we selected a time window in which the frequency of the lowest harmonic was stable. The spectrogram of the corresponding note was calculated and the frequency of its lowest harmonic was estimated within this time window. To improve the resolution of this frequency estimate, we performed a piecewise cubic spline interpolation of the mean spectrogram around its peak. We evaluated variability in the frequency of the lowest harmonic by calculating the SD of its distribution over all clean renditions of the motif in each condition. The numbers of motif renditions considered were as follows: $81 \pm 38$ at baseline, $73 \pm 62$ during SCH23390 (SCH) infusion, and $57 \pm 28$ during saline infusion for female-evoked vocalizations (range 22-159); and $3300 \pm 2500$ at baseline, $1800 \pm 1600$ during SCH infusion, and $1800 \pm 1100$ during saline infusion for spontaneous vocalizations (range 470-5441).

For the subsyllabic element displayed below (see Fig. 10), we compared our estimate of the lowest harmonic with fundamental frequency estimates. There was a strong correlation between the results of the two methods $\left(R_{2}=0.98, n=1000\right.$ randomly sampled songs).

Both context and treatment might affect the location of the bird when singing and its variability, inducing fluctuations of signal amplitude. To rule out an influence of the location of the bird on song variability, we calculated the correlation between our measure of the frequency of the lowest harmonic and random fluctuations of signal amplitude. We found no correlation between the signal amplitude and the frequency of the lowest harmonic for the subsyllabic element displayed below (see Fig. 10) $\left(R_{2}=0.07, n=1000\right.$ randomly sampled songs).

Statistics. Numerical values are given as mean \pm SD, unless stated otherwise. Response latency, strength, and duration before and after drug injections were compared using a paired $t$ test. In addition, for each cell, spontaneous activity over multiple trials was compared before and 
after drug injection using a paired $t$ test. For the behavioral experiment, the coefficient of variation $(\mathrm{CV})$ of the frequency of the lowest harmonic (CVFLH) of subsyllabic elements and relative frequency variability were compared across different conditions using paired $t$ tests. For each paired $t$ test applied, we report the associated $p$ value (the probability of observing the given result, or one more extreme, by chance if the null hypothesis is true), the value of the test statistic $(t)$, and the degrees of freedom of the test (df).

\section{Results}

\section{DA decreases song responses in BG} output neurons

We first investigated the effects of DA on responses evoked by song playback in Area X pallidal neurons, most of which project to the thalamic nucleus DLM (Leblois et al., 2009). As described previously (Doupe, 1997; Solis and Doupe, 1997; Person and Perkel, 2007; Gale and Perkel, 2010), pallidal neurons increased their firing rate in response to playback of the bird's own song (BOS), with an average response strength of $8.4 \pm 5.1 \mathrm{sp} / \mathrm{s}$ $(n=13)$. Other sound stimuli (noise, conspecific song, and BOS played in reverse) evoked weaker responses. We measured the selectivity of responses to BOS in pallidal neurons with the discriminability index $d^{\prime}$, which averaged $1.6 \pm 0.9$ $(n=10)$, significantly greater than $0(p<$ $0.001, t=5.2, \mathrm{df}=9$ ).

Injection of DA into Area X suppressed responses to BOS playback in Area X pallidal cells (Fig. $1 B, C$ ). Overall, the BOS response strength after DA injection was significantly lower than under control conditions (from $8.9 \pm 5.6$ to $2.2 \pm 1.3 \mathrm{sp} / \mathrm{s}, n=7$, $p=0.01, t=3.5, \mathrm{df}=6$ ) (Fig. $1 D)$, and the selectivity of the remaining responses was significantly decreased ( $d^{\prime}$ from $1.4 \pm 1$ to $-0.2 \pm 0.4, p=0.02, t=3.2, \mathrm{df}=6)$ and not different from 0 $(p>0.1, t=-1.4, \mathrm{df}=6)$. Similarly, injections of the $\mathrm{D}_{1}$ receptor agonist SKF38393 (SKF) in Area X suppressed song responses in Area X (BOS response strength: from $10.1 \pm 3.9$ to $2.9 \pm 1.4 \mathrm{sp} / \mathrm{s}, n=3, p=0.04, t=5, \mathrm{df}=2 ; d^{\prime}$ : from $2.1 \pm 0.5$ to $0.1 \pm 1.6, p=0.1, t=3, \mathrm{df}=2)$. Responses returned after washout of the drug in six of seven neurons following DA (BOS response strength: $\left.9.7 \pm 7.6 \mathrm{sp} / \mathrm{s}, d^{\prime}: 0.7 \pm 1.5\right)$ injection and one of three neurons following SKF38393 injection (BOS response strength: $\left.5.8 \mathrm{sp} / \mathrm{s}, d^{\prime}:-1\right)$. In contrast to dopaminergic drugs, injection of saline did not modify the response of pallidal neurons to BOS playback (BOS response strength: from $5.5 \pm 4.1$ to $6.7 \pm$ $3, n=3, p>0.1, t=-1.3, \mathrm{df}=2 ; d^{\prime}$ : from $2.3 \pm 3$ to $1.6 \pm 0.9$, $p>0.5, t=0.5, \mathrm{df}=2$ ) (Fig. $1 E$ ). Changes in song response under DA were often accompanied by increased spontaneous activity (Fig. $1 B$ ) (see next section for extensive analyses of changes in spontaneous activity). It is possible that elevated firing rates contributed in some cases to decreased responses in pallidal neurons due to a ceiling effect. Responses to BOS playback were strongly suppressed in Area X pallidal neurons, however, even when spontaneous activity was not affected $(n=3 / 7$ under DA and $1 / 3 \mathrm{SKF}$ ) (Fig. 1 C,D). Moreover, there was a complete lack of correlation between increase in spontaneous firing rate and reduction in song response $\left(R^{2}=0.002\right)$.

In summary, DA injection in Area X of urethane-anesthetized zebra finches strongly dampened responses of Area $\mathrm{X}$ pallidal neurons to song playback.

\section{DA increases intrinsic activity in BG output neurons through $\mathrm{D}_{1}$ receptors}

We further examined the effects of DA on spontaneous firing of Area $\mathrm{X}$ neurons using a combination of in vivo and in vitro electrophysiological recordings. In vivo, Area $\mathrm{X}$ pallidal neurons displayed high spontaneous activity (mean firing rate: $58 \pm 15 \mathrm{sp} / \mathrm{s}, n=24$ ). Spontaneous activity was significantly increased by DA injection in Area $\mathrm{X}$ in most pallidal neurons (10/15) (Fig. 3A) and decreased in only 1 neuron. Overall, DA significantly increased spontaneous activity by $5 \mathrm{sp} / \mathrm{s}$ ( to $63 \pm 14 \mathrm{sp} / \mathrm{s}, n=15, p=0.001, t=-3, \mathrm{df}=14$ ), which recovered after washout $(60 \pm 13 \mathrm{sp} / \mathrm{s}, p=0.04, t=-2.2$, $\mathrm{df}=14$ ). Concerning putative Area X interneurons, the effect of DA on spontaneous firing rate was not consistent (Fig. $3 B$ ). Spontaneous activity was decreased in two such cells, increased in one, and unchanged in two. In vivo injections of the $\mathrm{D}_{1}$ receptor agonist SKF38393 appeared to have similar effects on pallidal spontaneous activity as DA, increasing spontaneous firing rate in most neurons, although the increase was significant in only four of nine cells, and the overall change in average firing rate was not significant (Fig. 3C).

In vitro, DA increased the intrinsic firing rate of putative pallidal cells, defined as cells displaying a spontaneous firing rate of 
$>10 \mathrm{sp} / \mathrm{s}$. DA significantly increased the firing rate from $19 \pm 8$ to $22 \pm 9 \mathrm{sp} / \mathrm{s}(n=18, p=0.005, t=-3.2, \mathrm{df}=17)($ Fig. $3 D)$. Because these recordings were made in the presence of the ionotropic glutamate and $\mathrm{GABA}_{\mathrm{A}}$ receptor blockers kainic acid and picrotoxin, respectively, the effect of DA was likely direct on pallidal neurons rather than through indirect circuit effects. This increase in firing rate was mimicked by application of the $D_{1}$ receptor agonist SKF38393 (from $19 \pm 3$ to $27 \pm 17 \mathrm{sp} / \mathrm{s}, n=11$, significant only when the cell with the largest increase was excluded: $p=0.001, t=-5, \mathrm{df}=8)$. The effect of DA was blocked by prior application of the $\mathrm{D}_{1}$ receptor antagonist SCH23390 (from $19 \pm 8$ to $20 \pm 10 \mathrm{sp} / \mathrm{s}, n=7, p=0.2, t=0.8$, $\mathrm{df}=6$ ). The $\mathrm{D}_{2}$ receptor agonist quinpirole had no effect (from $17 \pm 6$ to $17 \pm$ $6 \mathrm{sp} / \mathrm{s}, n=5, p=0.9, t=-0.1, \mathrm{df}=4)$.

These results indicate that $\mathrm{DA}$, acting via $\mathrm{D}_{1}$ receptors, increases the intrinsic spontaneous activity of Area X pallidal neurons.

\section{DA decreases responses in Area X to HVC electrical stimulation}

Area X receives auditory input from nucleus HVC. Area X pallidal neurons receive direct excitatory input from HVC as well as feedforward inhibition via Area X interneurons (Farries et al., 2005). The reduction of song-evoked responses in Area X pallidal neurons might rely on change in the responsiveness of Area $\mathrm{X}$ neurons to their direct input from HVC. To test whether DA modulates the responsiveness of Area $\mathrm{X}$ neurons to their input from HVC, we recorded the response of Area X neurons to HVC electrical stimulation (see Leblois et al., 2009) before and after DA injection in Area X.

DA suppressed the rapid excitation evoked by HVC stimulation in Area X pallidal neurons (Fig. $4 A, B$ ) sometimes revealing or increasing an inhibitory component of the response (Fig. $4 A$ ). DA injection suppressed the peak of the population average of responses to HVC stimulation (Fig. 4C). Over all neurons, the average peak response dropped from $363 \pm 133$ to $190 \pm 103 \mathrm{sp} / \mathrm{s}$ after DA injection $\left(n=16, p<10^{-4}, t=6\right.$, df $\left.=15\right)$ and recovered to $357 \pm 143$ after washout. Moreover, the stimulation response strength over a $30 \mathrm{~ms}$ window following HVC stimulation dropped from $49 \pm 24$ to $3 \pm 23 \mathrm{sp} / \mathrm{s}\left(p<10^{-6}, t=10.8\right.$, $\mathrm{df}=15)$, and recovered after washout to $47 \pm 27 \mathrm{sp} / \mathrm{s}$ (Fig. $4 D)$. To provide a fuller description of the data, we also examined the relative area (see methods) and duration of the excitatory and inhibitory components of the responses. For each response feature, a $t$ test revealed a significant change between the baseline and DA conditions. A false discovery rate analysis indicates that some of the tests are at the threshold for statistical significance (threshold $p$ value of 0.04 ). DA decreased both the relative area and the duration of the excitatory components in the response of pallidal neurons to HVC stimulation (excitation relative area: from $112 \pm 61 \%$ to $32 \pm 27 \%, p=10^{-5}, t=6.6, \mathrm{df}=15$ ) (Fig. $4 E$ ) (excitation duration: from $18 \pm 11 \mathrm{~ms}$ to $9 \pm 5 \mathrm{~ms}, p=0.004$, $t=3.4, \mathrm{df}=15$ ) (Fig. $4 F$ ). These values recovered after washout (excitation relative area: $90 \pm 54 \%$; excitation duration: $16 \pm 9 \mathrm{~ms}$ ). The inhibitory components in response to HVC stimulation were larger and longer in duration after DA injection (inhibition relative area: from $3 \pm 5 \%$ to $11 \pm 11 \%, p=0.03, t=2.4, \mathrm{df}=15$ ) (Fig. 4G) (inhibition duration from $2 \pm 3 \mathrm{~ms}$ to $5 \pm 4 \mathrm{~ms}, p=$ $0.04, t=-2.1$, df $=15$ ) (Fig. $4 H$ ), and recovered after washout (inhibition relative area: $5 \pm 7 \%$; inhibition duration: $3 \pm 4 \mathrm{~ms}$ ). Overall, DA decreased the response of pallidal neurons to HVC stimulation, reducing the excitatory component of the responses and emphasizing their inhibitory component.
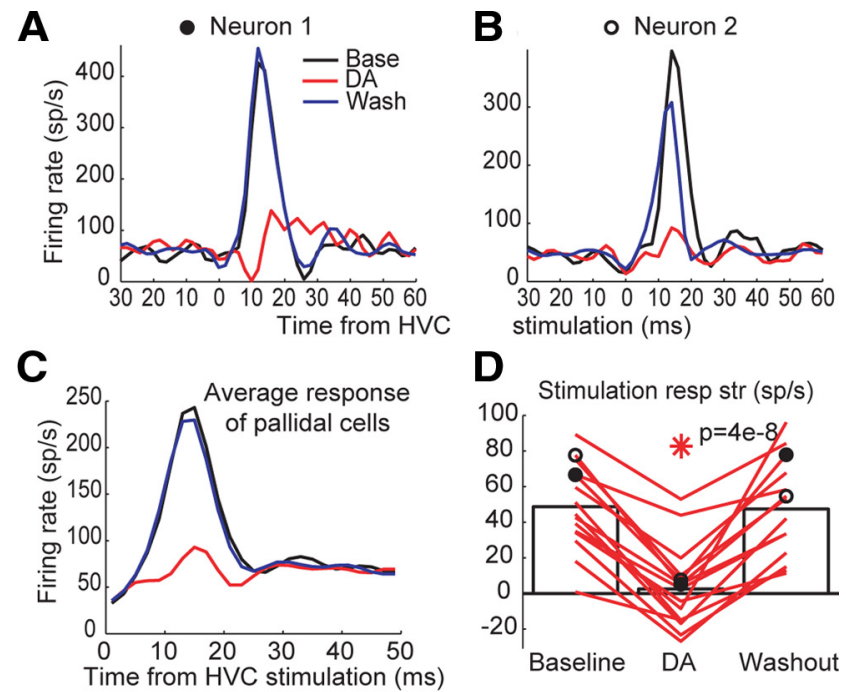

E
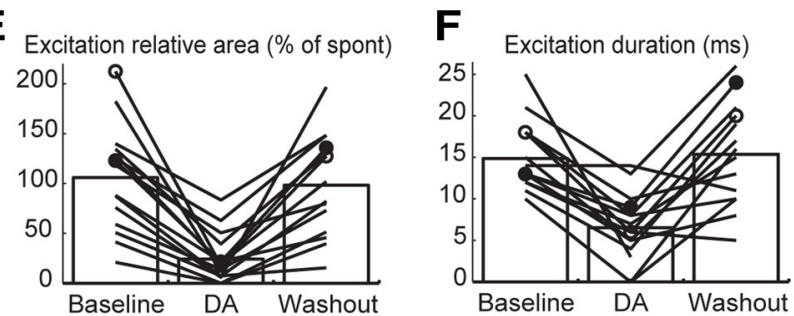

G

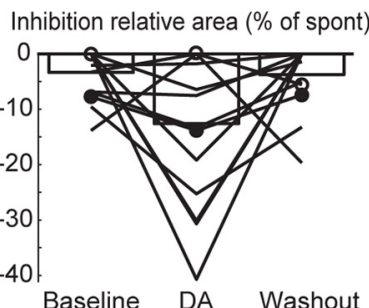

$\mathbf{H}$
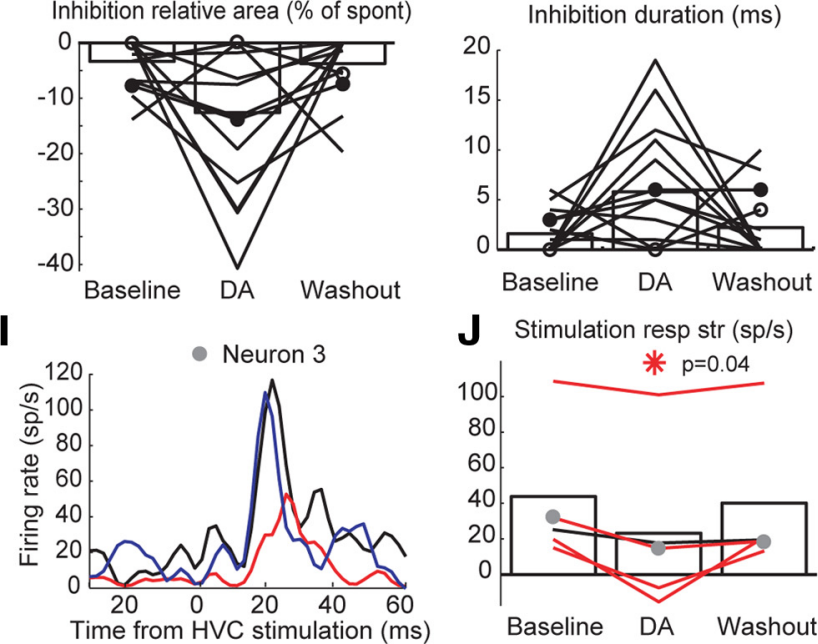

Figure 4. DA decreases the response of Area X neurons to HVC stimulation. $A, B$, Changes in the response to HVC stimulation following DA injection in the two Area $X$ neurons displayed in Figure 1, $B(\boldsymbol{A})$ and $C(\boldsymbol{B})$. Each panel depicts the PSTH at baseline (black), following DA injection (red), and after washout (blue). C, Average response to HVC stimulation over all Area X pallidal cells at baseline (black), following DA injection in Area X (red) and after washout (blue). $\boldsymbol{D}-\boldsymbol{H}$, Quantification of responses to HVC stimulation before and after DA injection in Area X in all pallidal neurons. $\boldsymbol{D}$, Stimulation response strength. $\boldsymbol{E}$, Excitation relative area (see Materials and Methods). $\boldsymbol{F}$, Duration of the excitatory component of the response. $\boldsymbol{G}$, Inhibition relative area (see Materials and Methods). $\boldsymbol{H}$, Duration of the inhibitory component of the response. Filled circles in $\boldsymbol{D} \mathbf{- H}$ indicate values corresponding to the neuron shown in $\boldsymbol{A}$ (same neuron as in Fig. 1A). Empty circles in $\boldsymbol{D}-\boldsymbol{H}$ indicate values for the neuron shown in $\boldsymbol{B}$ (same neuron as in Fig. $1 \boldsymbol{B}$ ). Overall, excitatory responses to HVC stimulation are suppressed by DA application, sometimes revealing an inhibitory component in the response. $I$, Change of the response to $H V C$ stimulation following DA injection in Area $X$ in a putative interneuron. Same conventions as in $\boldsymbol{A}$ and $\boldsymbol{B}$. $J$, Quantification of responses to HVC stimulation before and after DA injection in Area X in all Area X putative interneurons. Gray discs in J indicate values for the neuron shown in I. The stimulation response strength is diminished under DA in putative interneurons, although the decrease in response is less pronounced than in pallidal neurons. 
In putative interneurons, DA decreased the rapid evoked excitation to a lesser extent (Fig. 4I). In these neurons, the stimulation response strength decreased only slightly on average, from $44 \pm 44 \mathrm{sp} / \mathrm{s}$ at baseline to $23 \pm 53 \mathrm{sp} / \mathrm{s}$ $(n=5, p=0.03, t=4.1, \mathrm{df}=3)$ (Fig. $4 \mathrm{~J})$, and recovered after washout to $40 \pm 45$ $\mathrm{sp} / \mathrm{s}$. DA did not cause a significant change in the response peak in interneurons (from $373 \pm 183$ to $268 \pm 256 \mathrm{sp} / \mathrm{s}$ ).

DA thus reduced the responses of all Area X neurons to HVC electrical stimulation, and the response reduction was more pronounced in pallidal neurons.

\section{DA reduces pallidal neuron response to direct HVC inputs}

To dissect the mechanisms by which DA reduces the response of pallidal neurons to song and to HVC electrical stimulation, we studied the effects of DA in an in vitro preparation. Stimulation of HVC fibers innervating Area $\mathrm{X}$ led to a rapid and strong increase in firing in Area X putative pallidal neurons (see Materials and Methods). These responses were suppressed by application of the glutamate AMPA receptor antagonist CNQX (Fig. 5A). CNQX strongly decreased the stimulation response strength from $49 \pm 13$ to $9 \pm 14$ $\mathrm{sp} / \mathrm{s}(n=4, p=0.03, t=5.4, \mathrm{df}=3)$ (Fig. $5 B)$. Stimulation response strength recovered after washout $(27 \pm 13 \mathrm{sp} / \mathrm{s})$. The response peak also decreased in the presence of CNQX, from $140 \pm 40$ to $33 \pm 25$ $\mathrm{sp} / \mathrm{s}(p=0.02, t=4.7, \mathrm{df}=3)$, and recovered after washout to $85 \pm 34 \mathrm{sp} / \mathrm{s}$. Conversely, responses were unaffected by the cholinergic receptor antagonists mecamylamine and atropine (stimulation response strength from $32 \pm 19$ to $27 \pm 14$ $\mathrm{sp} / \mathrm{s}, n=4, p>0.5, t=0.9, \mathrm{df}=2$; response peak from $92 \pm 53$ to $75 \pm 51 \mathrm{sp} / \mathrm{s}$, $p>0.05, t=1.2, \mathrm{df}=2$ ) (Fig. 5C). Therefore, responses of pallidal neurons to HVC fiber stimulation in vitro were mediated by glutamate, similar to responses to HVC stimulation in vivo (Leblois et al., 2009).

As observed in vivo, DA application also diminished responses of pallidal neurons to stimulation of HVC fibers in vitro (Fig. 5D). Stimulation response strength was decreased from $20 \pm 18 \mathrm{sp} / \mathrm{s}$ at baseline to $9 \pm 8 \mathrm{sp} / \mathrm{s}$ under DA $(n=8, p=0.01, t=3.5, \mathrm{df}=7)$ (Fig. $5 E)$, and recovered after washout ( $17 \pm 15 \mathrm{sp} / \mathrm{s})$. Response peaks also strongly decreased, from $102 \pm 40 \mathrm{sp} / \mathrm{s}$ at baseline to $54 \pm 31 \mathrm{sp} / \mathrm{s}$ under DA ( $p=0.002, t=4.8, \mathrm{df}=7$ ), and recovered to $84 \pm 44$ $\mathrm{sp} / \mathrm{s}$ after washout. In the presence of the $\mathrm{GABA}_{\mathrm{A}}$ blocker picrotoxin, DA still diminished pallidal responses to HVC fiber stimulation (Fig. $5 F$ ). Stimulation response strength decreased from $30 \pm 35 \mathrm{sp} / \mathrm{s}$ at baseline to $13 \pm 19 \mathrm{sp} / \mathrm{s}$ under DA $(n=13, p=$ $0.01, t=2.3, \mathrm{df}=12$ ) (Fig. $5 G$ ), and recovered to $36 \pm 49 \mathrm{sp} / \mathrm{s}$ after washout. Similarly, peak response decreased from $94 \pm 60$
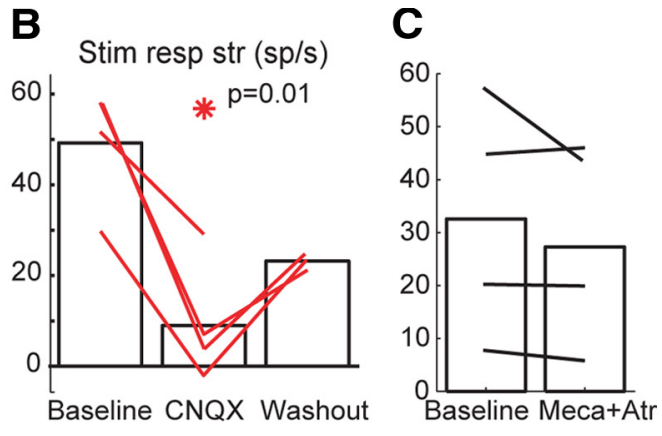

E Stimulation response strength (sp/s)

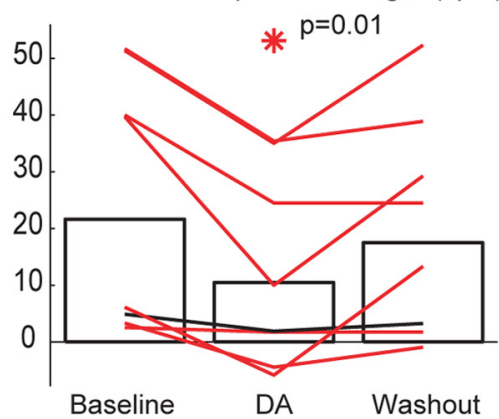

Under Picrotoxin

G

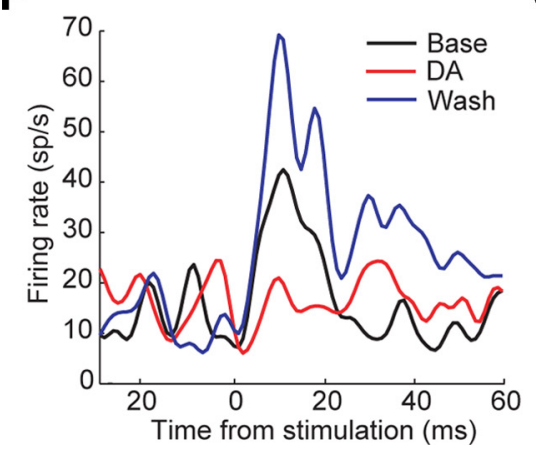

Stimulation response strength $(\mathrm{sp} / \mathrm{s})$

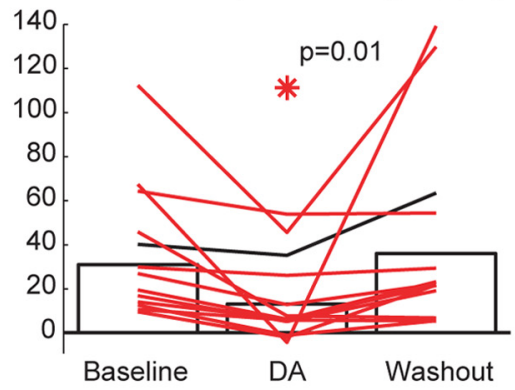

Figure 5. DA reduces the response of pallidal neurons to their excitatory inputs from HVC. $A$, Example response of a pallidal cell to HVC fiber stimulation in vitro before (black), during CNQX infusion (red), and after washout (blue). $\boldsymbol{B}$, Strength of the response to HVC fiber stimulation in all pallidal neurons before, during, and after CNQX perfusion. The response to stimulation was abolished by mecamylamine and atropine infusion. Cholinergic blockers did not modify the response of pallidal neurons to stimulation. ple of a pallidal response to HVC fiber stimulation before (black), during (red), and after (blue) DA infusion. $\boldsymbol{E}$, Over all 列 neurons, DA reduces the strength of the response to HVC fiber stimulation in the presence of picrotoxin.

$\mathrm{sp} / \mathrm{s}$ at baseline to $59 \pm 44 \mathrm{sp} / \mathrm{s}$ under DA $(p=0.02, t=2.6, \mathrm{df}=$ $12)$ and recovered after washout $(94 \pm 60 \mathrm{sp} / \mathrm{s})$. Therefore, the DA-induced decrease in the response of pallidal neurons to HVC stimulation was not solely due to a change in the feedforward inhibition received by pallidal neurons. Instead, DA decreased the effect of direct excitatory input from HVC on the firing of pallidal neurons.

\section{$D_{1}$ receptors mediate the $\mathrm{DA}$ effect on pallidal} neuron responses

We then sought to determine the DA receptor type underlying the effect of DA on the response of pallidal neurons to HVC inputs. Prior application of the $\mathrm{D}_{1}$ receptor antagonist SCH23390 blocked the effect of DA on the HVC electrical stimulation excitation of Area X pallidal neurons (Fig. 6A). Over all, the stimu- 

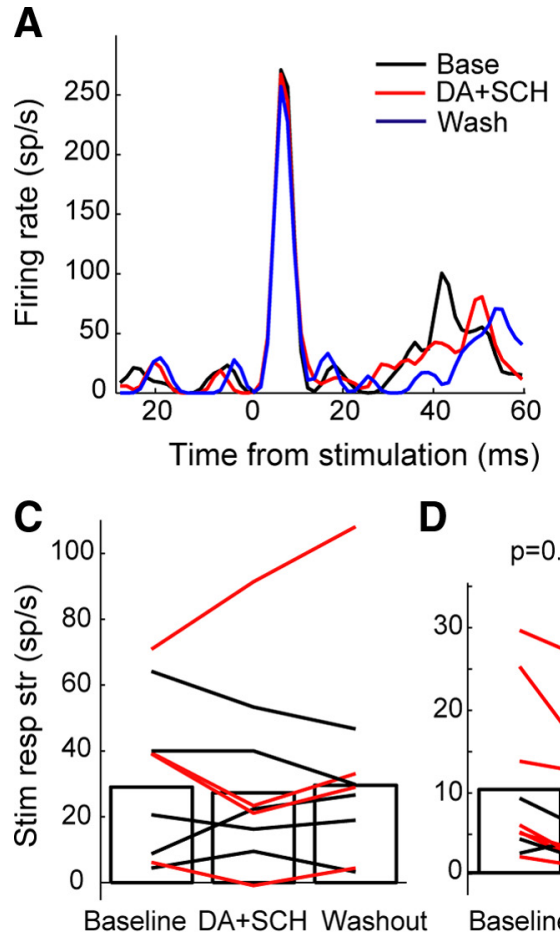

D
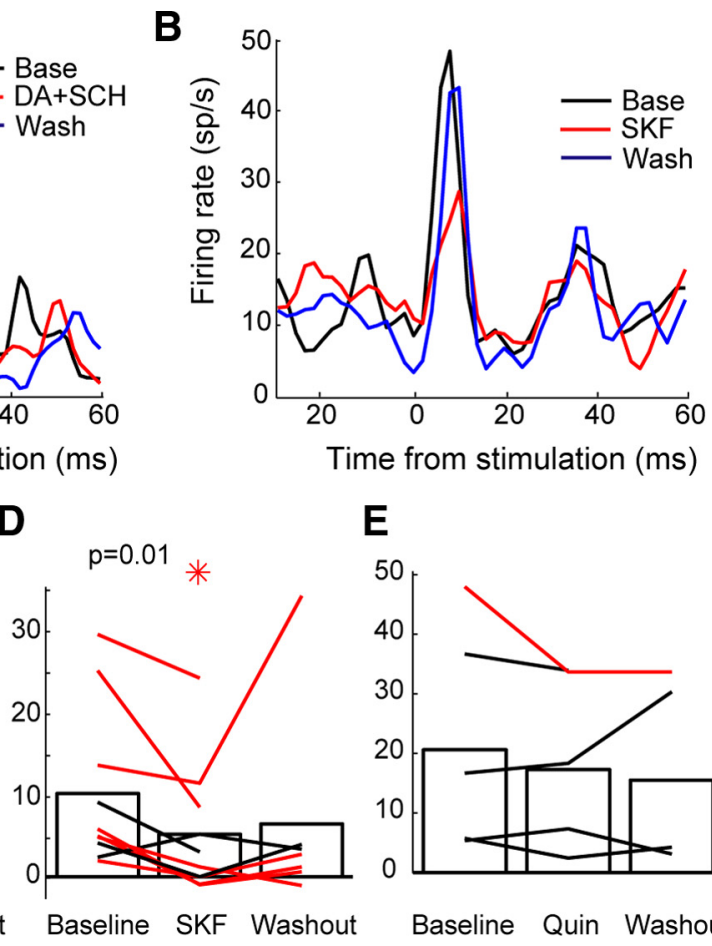

\section{E}

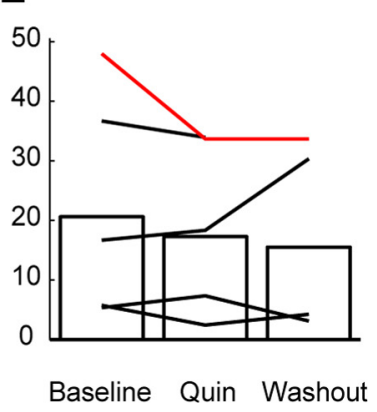

Figure 6. DA reduces the response of pallidal neurons to HVC stimulation by acting through $D_{1}$ receptors. $A$, Example of a pallidal response to HVC fiber stimulation before (black), during (red), and after (blue) infusion of DA and SCH23390. SCH23390 was applied first for 2-5 min, followed by $5 \mathrm{~min}$ of SCH23390+DA. B. Example response of a pallidal neuron to HVC stimulation before (black), during (red), and after (blue) SKF38393 infusion. C, Strength of the response to HVC stimulation in all pallidal neurons before, during, and after DA and SCH23390 infusion. Over all putative cells, DA did not change the response to stimulation when it was preceded by the infusion of the $D_{1}$-type receptor blocker SCH23390. D , Strength of the response to HVC stimulation in all pallidal neurons before, during, and after SKF38393 infusion. Over all pallidal cells, the $D_{1}$-type receptor agonist SKF38393 tended to decrease the response of pallidal neurons to stimulation. $\boldsymbol{E}$, Strength of the response to HVC stimulation in all pallidal neurons before, during, and after quinpirole infusion. The $D_{2}$ receptor agonist quinpirole did not change the response of pallidal neurons to HVC stimulation.

lation response strength was unchanged by DA in the presence of $\mathrm{SCH} 23390$ (from $29 \pm 20$ to $26 \pm 26 \mathrm{sp} / \mathrm{s}, n=9, p=0.9, t=0.06$, $\mathrm{df}=8$ ) (Fig. 6C). The response peak was also unchanged (from $134 \pm 47$ to $129 \pm 52 \mathrm{sp} / \mathrm{s}, p=0.6, t=0.8, \mathrm{df}=8$ ). Moreover, the $\mathrm{DA}_{1}$ receptor agonist SKF38393 mimicked DA and reduced the response to HVC fibers stimulation in pallidal neurons (Fig. 6B). SKF38393 strongly decreased the stimulation response strength (from $10 \pm 10$ to $5 \pm 8 \mathrm{sp} / \mathrm{s}, n=10, p=0.01$, $t=2.3$, $\mathrm{df}=9$ ) (Fig. $6 \mathrm{D}$ ) as well as the response peak (from $77 \pm 37$ to $53 \pm 35 \mathrm{sp} / \mathrm{s}, p=0.03, t=2.7, \mathrm{df}=8)$. Both values recovered after washout (stimulation response strength: $7 \pm$ $12 \mathrm{sp} / \mathrm{s}$; response peak: $59 \pm 40 \mathrm{sp} / \mathrm{s}$ ). On the contrary, the $\mathrm{D}_{2}$ receptor agonist quinpirole did not change either the stimulation response strength (from $21 \pm 21$ to $17 \pm 17 \mathrm{sp} / \mathrm{s}, n=5, p=0.3$, $t=1.1, \mathrm{df}=4$ ) (Fig. $6 E$ ) or peak (from $120 \pm 17$ to $117 \pm 10 \mathrm{sp} / \mathrm{s}$, $p=0.8, t=0.2, \mathrm{df}=4$ ) of pallidal responses to HVC fiber stimulation.

Therefore, the DA-induced decrease in HVC-driven responses of Area X pallidal neurons is mediated by $\mathrm{D}_{1}$ receptors.

\section{DA reduces firing variability in Area $X$ pallidal neurons}

Because irregular firing in Area X pallidal neurons can drive firing in downstream thalamic neurons in nucleus DLM, we then investigated how DA affected the firing variability of Area X output pallidal neurons in vivo. We compared the variability in ISI duration in three different conditions: in spontaneous firing, in the response to song playback, and in the response to HVC electrical stimulation. In all cases, DA led to an increase in firing regularity as measured by a narrowing of the ISI distribution. Neurons whose firing rate increased after DA treatment displayed a shift in the peak of their ISI distribution (Fig. 7A). More importantly, the ISI distribution was much narrower after DA injection than it was at baseline or after washout, and the shortest and longest ISIs did not occur when DA was applied. Similarly, neurons that did not undergo a change in mean firing rate nevertheless displayed a narrowing of the ISI distribution after DA injection, with fewer short and long ISIs (Fig. 7B). Thus, DA application caused a narrowing of the mean ISI distribution over all Area X pallidal neurons examined (Fig. 7C), and the number of shorter and longer ISI was significantly decreased (ratio of ISIs $<8 \mathrm{~ms}$ : from $6 \pm 4 \%$ to $3 \pm 4 \%, p=0.005, t=$ 4.8 , df $=14$; ratio of ISIs $>25 \mathrm{~ms}$ : from $14 \pm 18 \%$ to $6 \pm 10 \%, p=0.01, t=2.1$, $\mathrm{df}=14)$. DA application decreased the $\mathrm{CV}$ of the ISI distribution in spontaneous activity in all Area $\mathrm{X}$ pallidal neurons (from $0.35 \pm 0.06$ to $0.24 \pm 0.06, n=15$, $\left.p<10^{-5}, t=9.6, \mathrm{df}=14\right)($ Fig. $7 D)$. The $\mathrm{CV}$ recovered after washout (to $0.3 \pm$ 0.05).

DA also decreased firing variability in response to song playback or in response to HVC stimulation. In response to playback of the BOS, the average ISI distribution narrowed (Fig. 7E), shorter ISIs became less frequent (ratio of ISIs $<8 \mathrm{~ms}$ : from $38 \pm 8 \%$ to $10 \pm 11 \%, p=10^{-7}, t=21.2$, $\mathrm{df}=6$ ), and the ISI CV was decreased (from $0.36 \pm 0.07$ to $0.2 \pm 0.06, n=7, p=$ $0.008, t=3.8, \mathrm{df}=6$ ) (Fig. $7 F$ ) after DA application. Similarly, DA application caused shorter ISIs in response to HVC stimulation to become less frequent (ratio of ISIs $<8 \mathrm{~ms}$ : from $29 \pm 12 \%$ to $\left.9 \pm 11 \%, p=10^{-6}, t=18.4, \mathrm{df}=14\right)($ Fig. $7 G)$, and the ISI CV increased over all Area X pallidal neurons (from $0.59 \pm 0.1$ to $0.42 \pm 0.12, n=15, p=0.002, t=4.2, \mathrm{df}=14)($ Fig. $7 H)$.

Overall, DA decreased the spontaneous and evoked firing variability in Area $\mathrm{X}$ pallidal neurons in vivo.

\section{DA decreases responses to song playback in LMAN}

Each thalamic neuron in nucleus DLM receives a tonic inhibitory input from a single Area X pallidal neuron. Its postinhibitory rebound properties make it likely to fire when a series of short ISIs in its pallidal input is followed by a longer ISI (Person and Perkel, 2005, 2007; Kojima and Doupe, 2009; Leblois et al., 2009). Therefore, thalamic firing, and, more generally, information transmission from HVC to LMAN, relies on a high variability in ISI duration of Area X pallidal neurons. Because DA decreases ISI length variability in Area $\mathrm{X}$ pallidal neurons, it is expected to impede information transmission along the AFP.

To test this hypothesis, we recorded evoked activity in nucleus LMAN before and after injecting DA into Area X. Consistent with our prediction, we found that DA reduced the response to song playback in LMAN neurons (Fig. 8A). Responses to playback of BOS were suppressed in all LMAN neurons recorded after DA 
A
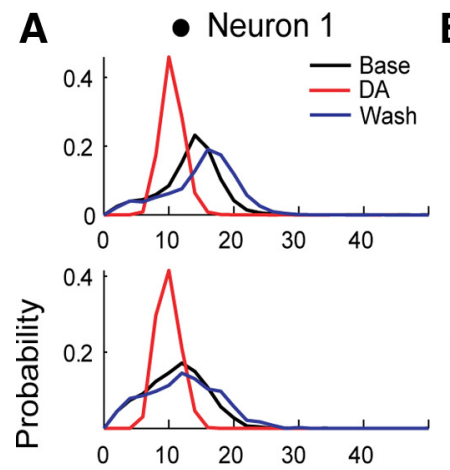

B $\circ$ Neuron 2
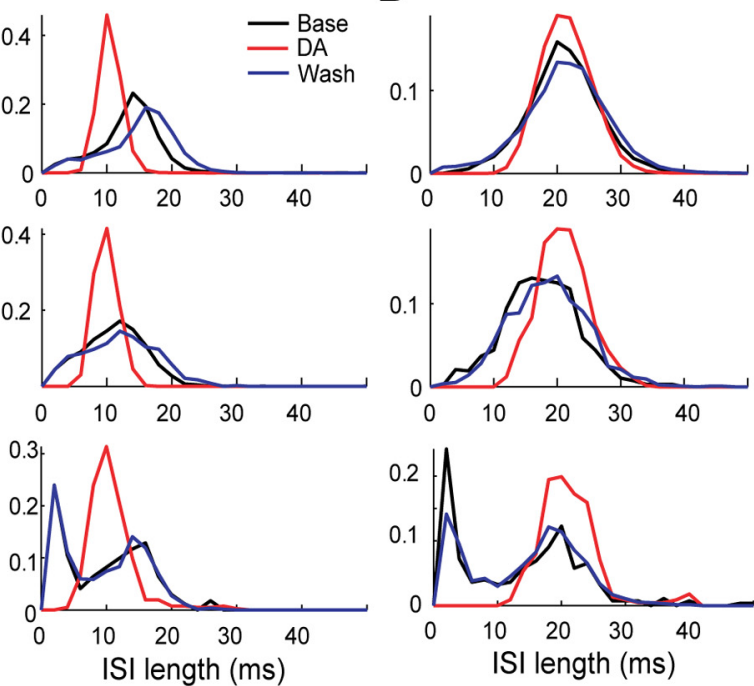

SI length (ms)
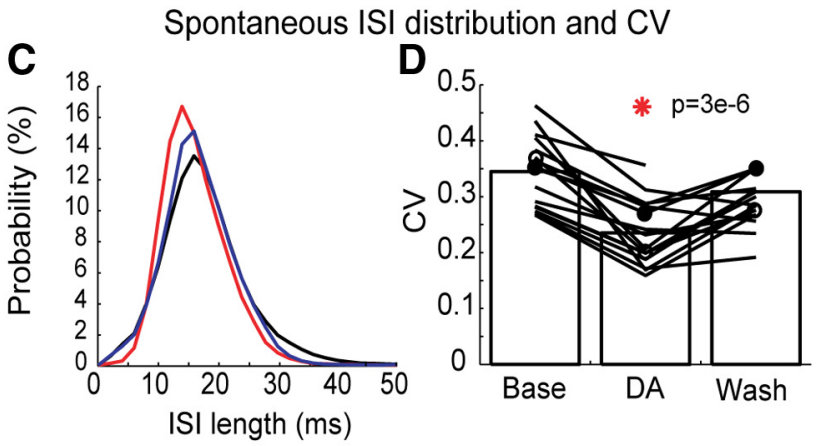

ISI distribution and $\mathrm{CV}$ in response to BOS playback

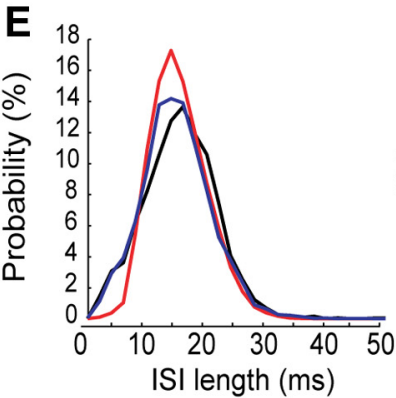

$\mathbf{F}$

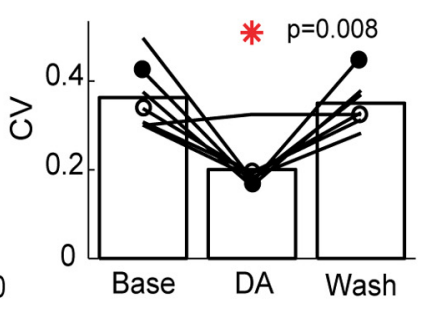

ISI distribution and CV following HVC stimulation (0-100ms)
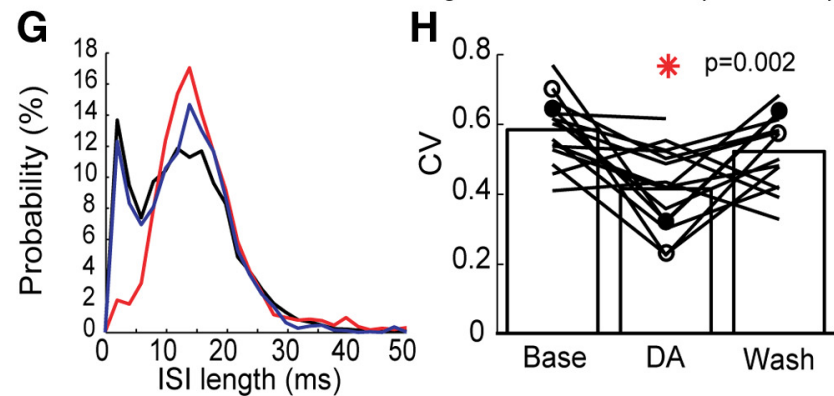

Figure 7. DA reduces the variability in the spontaneous and evoked firing of pallidal neurons. $A, B$, ISI distributions (top, in spontaneous activity; middle, in response to BOS playback; bottom, in response to HVC stimulation) for the two neurons shown in Figure 1, $B(\boldsymbol{A})$ and $C(\boldsymbol{B})$, at baseline (black), following DA injection in Area X (red), and after washout (blue). C, Average spontaneous ISI distribution over all pallidal neurons at baseline (black) and following DA injection in Area $X$ (red). D, DA injection in Area $X$ decreased the CV of the spontaneous ISI distribution in all pallidal neurons. $E$, Average ISI distribution in response to BOS playback over all pallidal neurons at baseline (black) and following DA injection in Area X (red). $F$, DA injection

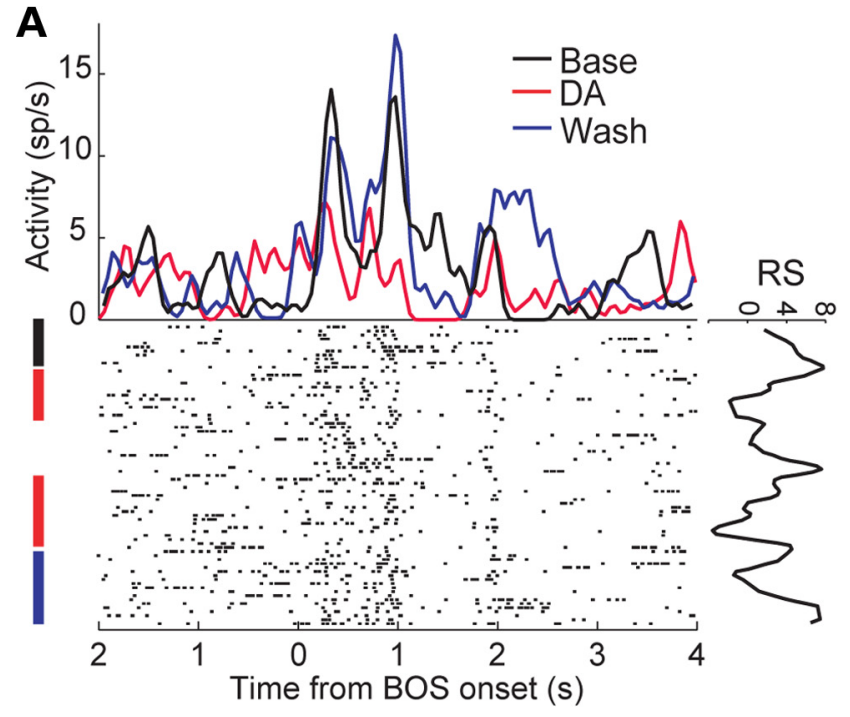

B
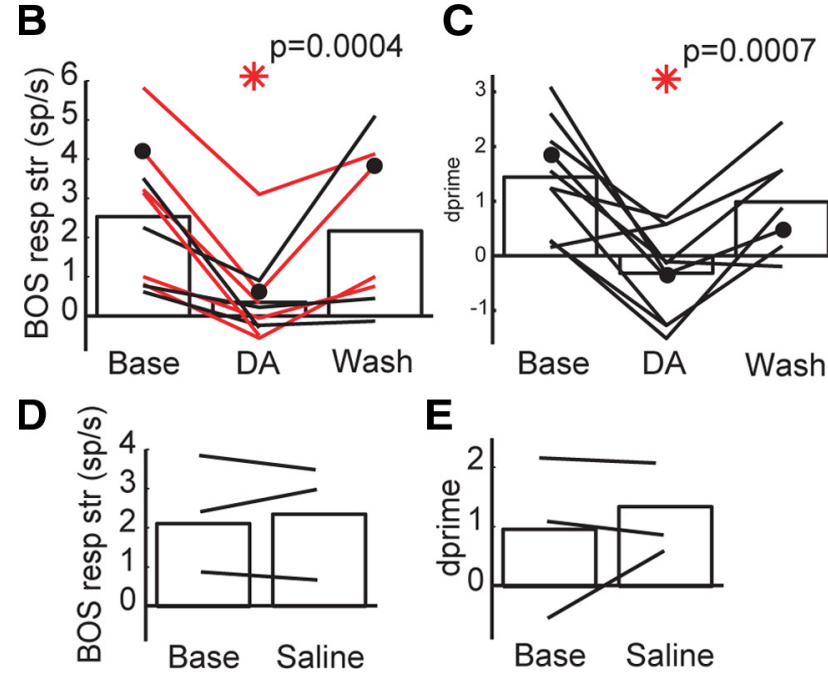

Figure 8. DA reduces response to BOS playback in LMAN neurons. $A$, Example response to BOS playback in a LMAN neuron before (black), during (red), and after (blue) two consecutive injections of DA in Area X. Left, PSTH (top) and raster (bottom). Black lines, Baseline: red lines, $D A$; blue lines, washout. Bottom right inset, BOS response strength as a function of time, aligned to the raster plot. $B, B O S$ response strength over all recorded LMAN neurons before and after DA injection in Area X. Red lines denote significant decreases in the BOS response strength. Over all LMAN neurons, DA application in Area $X$ strongly decreased the song BOS response strength. C, Selectivity in the response to song in LMAN was also strongly decreased by DA injection in Area $X$. Filled circles in $\boldsymbol{B}$ and $\boldsymbol{C}$ indicate values corresponding to the neuron shown in $\boldsymbol{A} . \boldsymbol{D}, \boldsymbol{E}$, Saline injections did not change the BOS response strength $(\boldsymbol{D})$ or selectivity index $\left[\boldsymbol{E}, d^{\prime}\right.$, (dprime)].

injection in Area X (BOS response strength: $2.6 \pm 1.8$ to $0.4 \pm 1.1$ $\mathrm{sp} / \mathrm{s}, n=10, p=0.0004, t=5.4, \mathrm{df}=9)($ Fig. $8 B)$, and recovered after washout (BOS response strength: $2.2 \pm 2.1 \mathrm{sp} / \mathrm{s}, n=7$ ). Not surprisingly, the selectivity of any remaining responses was also reduced $\left(d^{\prime}: 1.4 \pm 1.0\right.$ to $\left.-0.3 \pm 0.8, p=0.0006, t=5.1, \mathrm{df}=9\right)$

in Area $\mathrm{X}$ decreased the $\mathrm{CV}$ of the ISI distribution in response to BOS playback in all but one pallidal neuron. $\mathbf{G}$, Average ISI distribution in response to HVC stimulation over all pallidal neurons at baseline (black) and following DA injection in Area X (red). $\boldsymbol{H}$, Over all pallidal neurons, DA injection in Area $X$ decreased the CV of the ISI distribution in response to HVC stimulation. Filled circles in $\boldsymbol{D}, \boldsymbol{F}$, and $\boldsymbol{H}$ indicate $\mathrm{CV}$ values for the neuron shown in $\boldsymbol{A}$ (same neuron as in $1 A$ and $3 A$ ). Empty circles in $\boldsymbol{D}, \boldsymbol{F}$, and $\boldsymbol{H}$ indicate $(V$ values for the neuron shown in $B$ (same neuron as in $1 B$ and $3 B$ ). 
A

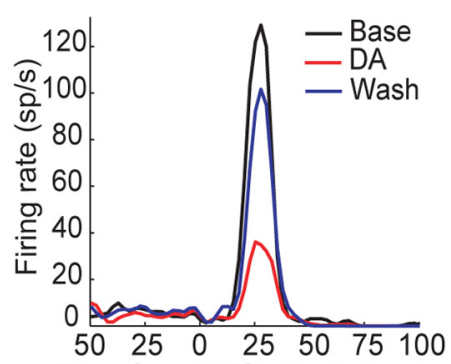

Time from HVC stimulation (ms)

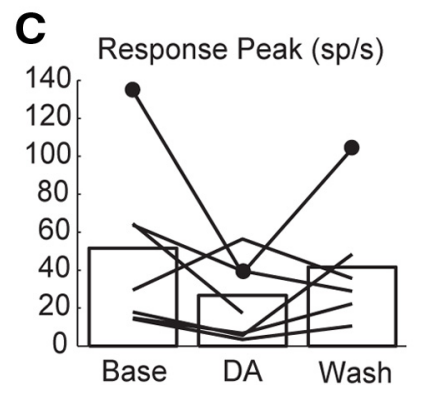

B

Stimulation resp str (sp/s)

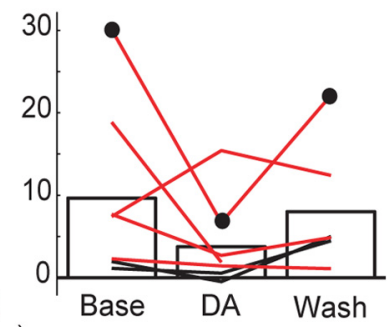

D Excitation duration (ms)

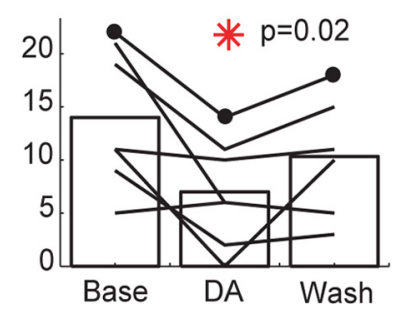

Figure 9. DA injection into Area $X$ decreases the response to HVC stimulation in most LMAN neurons. $\boldsymbol{A}$, Example of a neuron with decreased response to HVC stimulation following DA injection in Area X. Black, Baseline; red, DA; blue, washout. $B, C$, Stimulation response strength $(\boldsymbol{B})$ and response peak $(\boldsymbol{C})$ show that all but one LMAN neuron had a decreased response to HVC stimulation following DA injection in Area X. In $\boldsymbol{B}$, red lines denote a significant change from baseline. $\boldsymbol{D}$, The duration of LMAN responses was significantly decreased after DA injection in Area X. Black dots in $\boldsymbol{B}-\boldsymbol{D}$ indicate values corresponding to the neuron shown in $\boldsymbol{A}$.

(Fig. $8 C$ ), and recovered after washout $\left(d^{\prime}: 1 \pm 0.9\right)$. In contrast, saline injections in Area X did not modify the strength or selectivity of responses to BOS playback in LMAN neurons (BOS response strength: $2.1 \pm 1.6$ to $2.3 \pm 1.5 \mathrm{sp} / \mathrm{s}, n=3, p=$ $0.7, t=-0.6, \mathrm{df}=2 ; d^{\prime}: 1 \pm 1.2$ to $1.3 \pm 1, p=0.4, t=-0.2$, $\mathrm{df}=2)($ Fig. $8 D, E)$.

Responses of LMAN neurons to HVC electrical stimulation were also decreased after DA injections in Area X $(n=6 / 7)$ (Fig. $9 A)$. Overall, the stimulation response strength was $8 \pm 9 \mathrm{sp} / \mathrm{s}$ at baseline and $3 \pm 5 \mathrm{sp} / \mathrm{s}$ following DA injection in Area X, and recovered to $8 \pm 7 \mathrm{sp} / \mathrm{s}$ after washout (Fig. 9B). Moreover, the response peak was $48 \pm 44 \mathrm{sp} / \mathrm{s}$ at baseline and $23 \pm 20 \mathrm{sp} / \mathrm{s}$ under $\mathrm{DA}$, and recovered to $48 \pm 34 \mathrm{sp} / \mathrm{s}$ after washout (Fig. $9 \mathrm{C}$ ). These decreases in stimulation response strength and response peak were not significant due to one neuron that showed an increased response after DA was injected in Area X. Interestingly, DA injections in Area X significantly decreased the duration of the response to HVC electrical stimulation in LMAN neurons (from $28 \pm 13 \mathrm{~ms}$ to $14 \pm 10 \mathrm{~ms}, n=7, p=$ 0.02, $t=3.4, \mathrm{df}=6$ ) (Fig. 9D).

Spontaneous activity in DLM and in LMAN is expected to decrease following DA injection due to the shorter and less variable length of ISIs in DLM inhibitory input from Area X. Surprisingly, spontaneous activity in LMAN was not affected by DA injection in Area X (from $2.3 \pm 1.4$ to $2.3 \pm 1.6 \mathrm{sp} / \mathrm{s}, n=17, p=$ $0.9, t=0.7, \mathrm{df}=6$ ), suggesting that LMAN spontaneous activity may not rely on its input from DLM. Alternatively, the relation between spontaneous activity in DLM and in Area X output neurons may be more complex than expected.

\section{Activation of $D_{1}$ receptors in the $B G$ decreases song variability}

Levels of extracellular DA measured in Area X differ in different social contexts (Sasaki et al., 2006). Because DA can modulate the amplitude of the output of the AFP through its effects in Area X, mostly through $D_{1}$ receptors, it is a good candidate to trigger variability changes depending on the social context. To test this hypothesis, we blocked $\mathrm{D}_{1}$ receptors in Area X in behaving birds by slowly infusing the $\mathrm{D}_{1}$ receptor antagonist SCH23390 (1-2 $\mathrm{mm}$ ) into Area X. To measure differences in variability associated with different social contexts, we measured the frequency of harmonic components of syllables that displayed a clear harmonic structure (Fig. 10A). Consistent with previous reports (Kao et al., 2005; Kao and Brainard, 2006; Sakata and Brainard, 2008), we found that the frequency of the lowest harmonic was more variable when the male sang alone in the cage than when a female was present in the cage. The presence of a female decreased the CVFLH in 12 of 13 subsyllabic elements from four birds. Overall, the CVFLH was $0.019 \pm 0.01$ when a male sang alone, and $0.012 \pm 0.01$ in the presence of a female ( $p=0.001$, $t=4.4, \mathrm{df}=12)($ Fig. $10 \mathrm{D})$.

In line with our hypothesis, we found that infusion of the $\mathrm{D}_{1}$ receptor antagonist $\mathrm{SCH} 23390$ abolished changes in variability related to social context (Fig. 10C). Indeed, the CVFLH of all subsyllabic elements considered did not display any change in variability with social context when SCH23390 was infused in Area X $(0.020 \pm 0.011$ when singing alone versus $0.021 \pm$ 0.01 in the presence of a female, $p=0.5, t=0.7, \mathrm{df}=12$ ) (Fig. $10 \mathrm{D})$. Even when considering only subsyllabic elements showing context-dependent variability before surgery (12 of 13), no difference was found between the two social contexts (CVFLH of $0.19 \pm 0.007$ alone versus $0.18 \pm 0.008$ with a female, $p=$ $0.4, t=0.8, \mathrm{df}=11)$. The CVFLH during both social contexts after $D_{1}$ receptor blockade was not significantly different from the CVFLH in the absence of a female before drug infusion (in presence of a female: $p=0.9, t=0.2, \mathrm{df}=12$; in the absence of a female: $p=0.4, t=1$, df $=12$ ).

As a control, we infused saline in Area X before (one bird) or after (three birds) SCH23390 infusion. During saline infusion, the context-dependent song variability was restored, and the CVFLH was significantly lower in the presence of a female $(0.014 \pm 0.01$ versus $0.017 \pm 0.01$ alone, $p=0.02, t=3.9, \mathrm{df}=12$ ).

For each subsyllabic element displaying context-dependent variability in frequency, we compared the SD of the lowest harmonic frequency when the bird was singing to a female relative to the SD of the lowest harmonic frequency when singing alone before surgery. This relative song variability measure was strongly increased under SCH23390 infusion, from $57 \pm 16 \%$ to $96 \pm 29 \%(p=0.0004, t=5, \mathrm{df}=11)$, and partially recovered under saline infusion to $77 \pm 23 \%$ (Fig. $10 \mathrm{E}$ ).

We also calculated the mean CVFLH over all subsyllabic elements displaying context-dependent variability in frequency in each individual bird. Before surgery, the average per-bird CVFLH $(n=4)$ was significantly different in the absence or presence of a female $(0.017 \pm 0.004$ versus $0.010 \pm 0.002, p=0.04, t=3.5$, $\mathrm{df}=3$ ). During SCH23390 infusion, no significant difference was found between the two social contexts (average CVFLH of $0.018 \pm 0.004$ versus $0.016 \pm 0.005, p=0.7, t=0.6, \mathrm{df}=3$ ). The variability was significantly lower in the presence of a female during saline infusion (average CVFLH of $0.015 \pm 0.002$ alone versus $0.012 \pm 0.002$ with a female, $p=0.02, t=5$, df $=3$ ).

In addition, we were able to extract the fundamental frequency from a subset of subsyllabic elements that exhibited 

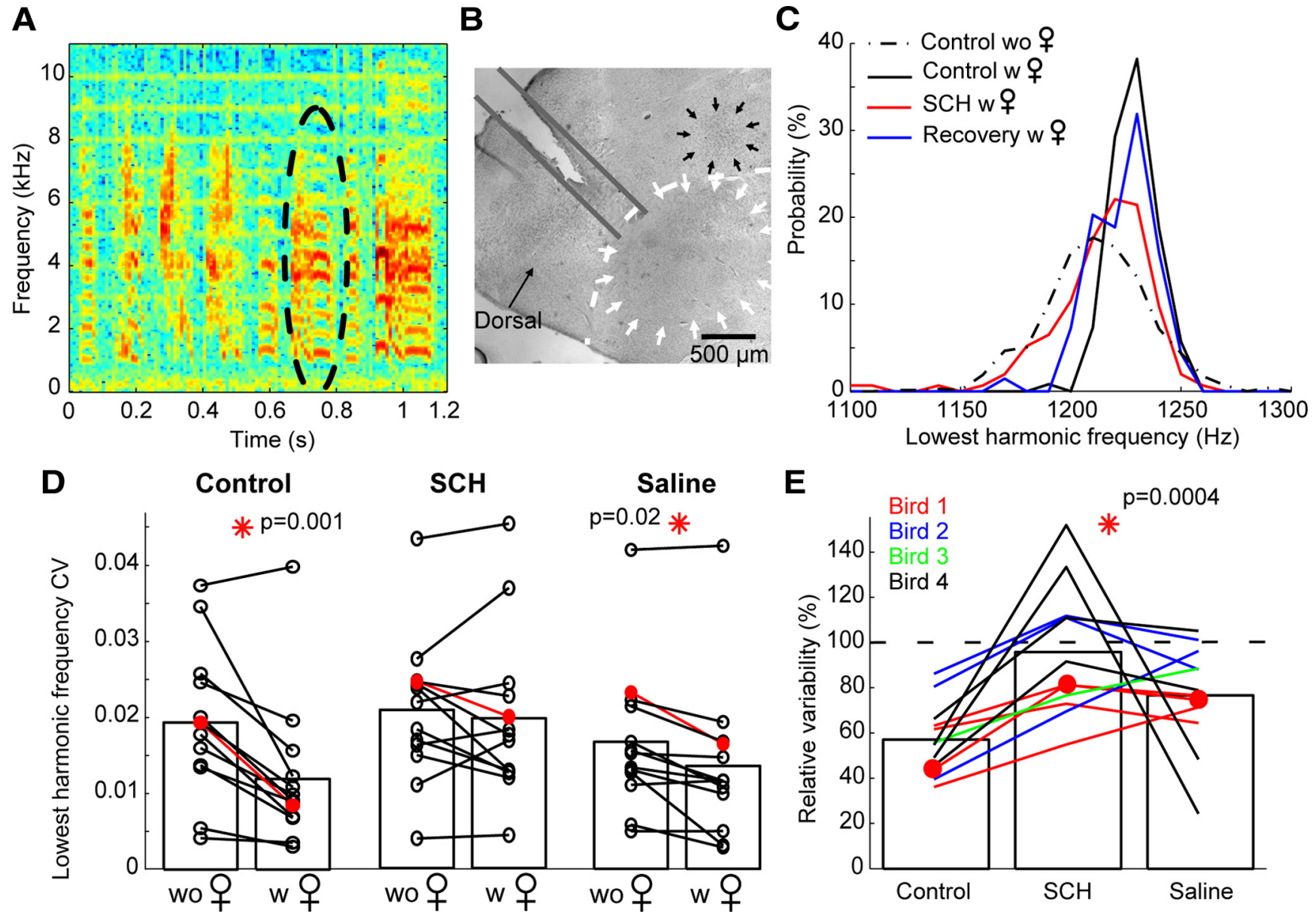

Figure 10. Infusion of the $\mathrm{D}_{1}$ receptor antagonist $\mathrm{SCH} 23390$ in Area X abolishes differences in song variability due to social context. $A$, Example of a song spectrogram of bird 1. This bird displayed five subsyllabic elements with a clear harmonic structure. The dashed ellipse indicates the subsyllabic element considered in $\boldsymbol{C}$. $\boldsymbol{B}$, cresyl violet staining of a $50 \mu \mathrm{m}$ parasagittal brain section showing the track of the cannula used to infuse drugs in the behaving bird. Solid gray lines denote the position of the cannula. Area X contours are outlined with white arrows, while LMAN is outlined with black arrows. The dashed white line outlines the pallial-subpallial lamina, which separates the BG from pallial structures. C, Distribution of the frequency of the lowest harmonic of the subsyllabic element highlighted in $A$ in four different conditions: in the absence of female before surgery (dotted dashed black line), in the presence of a female before surgery (solid black line), in the presence of a female during SCH23390 infusion in Area X (solid red line), and in the presence of a female during saline infusion in Area X (blue line, following the SCH23390 infusion). D, Context-dependent changes in song variability in three different conditions. In each paired graph, the left column refers to singing in the absence of female, while the right column refers to singing in the presence of a female. Left, Before surgery; middle, during the infusion of $\mathrm{SCH} 23390$; right, during saline infusion. Saline infusion followed SCH infusion in three of four birds. The two social contexts are associated with different song variability before surgery and during saline infusion, while $\mathrm{SCH}$ infusion abolishes differences in variability related to social context. $\boldsymbol{E}$, Relative song variability in the three behavioral conditions for the 12 subsyllabic elements displayed context-related changes in variability. The relative song variability is calculated as the SD of the lower harmonic frequency when the bird was singing to a female in each condition divided by the SD of the lowest harmonic frequency when singing alone before surgery. Left, Before surgery; middle, during the infusion of SCH23390; right, during saline infusion. In $\boldsymbol{D}$ and $\boldsymbol{E}$, the red discs indicate values corresponding to the subsyllabic element shown in $\boldsymbol{A}$ and $\boldsymbol{C}$.

harmonic stack structures. Under control conditions, the fundamental frequency of those eight elements, from three birds, was significantly lower in the presence of a female $(0.01 \pm$ $0.003)$ than when the bird was alone $(0.018 \pm 0.004 ; p=$ $0.0006, t=5.8, \mathrm{df}=7)$. When $\mathrm{D}_{1}$ receptors were blocked by infusion of SCH23390 in Area X, there was no longer any difference between the two social contexts $(0.02 \pm 0.01$ versus $0.021 \pm 0.006 ; p=0.6, t=0.5, \mathrm{df}=7$ ). The difference in variability was retained after saline infusion in Area X, with a $\mathrm{CV}$ of the fundamental frequency of $0.012 \pm 0.003$ in the presence of a female, and $0.015 \pm 0.004$ when the bird was alone ( $p=0.03, t=2.8, \mathrm{df}=7)$.

Other than the changes in song variability, there was an overall trend for mean frequency of the lowest harmonic to increase when a female was present in the cage ( $9 / 13$ subsyllabic elements showed an increase, $4 / 13$ a decrease). The frequency was therefore $17 \pm 27 \mathrm{~Hz}$ higher $(+0.8 \pm 1 \%, p=0.04, t=2.4, \mathrm{df}=12)$ when a female was present in the cage than when the male sang alone. Although previous studies in zebra finches did not report any change in average song features (Kao et al., 2005; Kao and Brainard, 2006), this increase in frequency is consistent with an increase in fundamental frequency reported in Bengalese finch singing to females (Sakata and Brainard, 2008).

In contrast to the variability measures, changes in the mean frequency of the lowest harmonic induced by SCH23390 infusion in Area X were not consistent among the 13 subsyllabic elements considered. During SCH23390 infusion, 9/13 subsyllabic elements sung in the absence of a female displayed an increase in their mean frequency of the lowest harmonic ( $8 / 13$ in the absence of a female), while $4 / 13$ displayed a decrease in mean frequency (5/13 in the absence of a female). Changes were not significant in either social context $(p>0.5, t=-0.3$, $\mathrm{df}=12)$.

These results indicate that the $\mathrm{D}_{1}$ receptor antagonist $\mathrm{SCH} 23390$ abolished social context-related song variability when infused in Area $\mathrm{X}$ without altering average song features. 


\section{Discussion}

We report here that delivering DA in the BG reduces the output of the AFP, a BG-thalamo-cortical circuit known to regulate song variability. $D A$ acts via $D_{1}$ receptors to reduce the response to HVC excitatory inputs in pallidal neurons, which provide BG output to the thalamus. Interfering with $\mathrm{D}_{1}$ receptor transmission abolishes social context-related changes in song variability. Our data indicate that DA triggers variability changes in song by modulating the amplitude of the AFP output signal through its action on $\mathrm{D}_{1}$ receptors in Area X.

\section{Mechanisms underlying DA effect in the BG}

DA modifies neuronal activity and synaptic transmission in the BG in mammals (Calabresi et al., 2000) and in birds (Ding and Perkel, 2002; Ding et al., 2003). Because the striatum receives the largest DA input in the BG in mammals (Smith and Villalba, 2008), previous studies have concentrated on DA effects on striatal neurons. Endogenous DA reduces responses to glutamate (Kiyatkin and Rebec, 1996, 1999) or to behaviorally relevant stimuli (Rolls et al., 1984; Nicola et al., 2000) mainly by acting on $\mathrm{D}_{1}$ receptors in mammalian striatal neurons. Similarly, in songbirds, $\mathrm{D}_{1}$ receptor activation depresses glutamatergic synaptic current in Area X spiny neurons (Ding and Perkel, 2002). Consistent with this effect, we found that DA decreases the response to HVC glutamatergic input in Area X putative interneurons, possibly including but not restricted to spiny neurons (which are thought not to project out of the nucleus). Area X inhibitory interneurons induce feedforward inhibition on pallidal neurons, shifting single spikes (Leblois et al., 2009). Therefore, the decreased responsiveness of Area X inhibitory interneurons under DA may partially underlie the increased regularity of evoked pallidal firing reported here.

Although DA innervation is much weaker in BG output nuclei than in the striatum in mammals, DA can directly affect the activity of BG output neurons (Kliem et al., 2007; Zhou et al., 2009). In vitro, DA increases spontaneous activity and firing regularity in nigral neurons through $\mathrm{D}_{1}$ receptors (Zhou et al., 2009), an effect similar to the effects reported here on avian pallidal neurons. In contrast, Kliem et al. (2007) reported an increase in GABA levels and a decrease in spontaneous activity mediated by $D_{1}$ receptors in pallidal and nigral neurons in vivo.

All previous studies focused on localized effects of DA in each BG structure, and it is difficult to predict how simultaneous DA release in several BG nuclei would globally modulate information transmission through the circuit. Because Area X includes both striatal neurons and pallidal-like output neurons, our study provides new insight on the integrated action of DA on the BG network as a whole.

\section{DA and social behaviors}

DA plays an important role in the modulation of social behavior, including display of social status (Miczek and Gold, 1983), defensive/submissive behavior (Puglisi-Allegra and Cabib, 1997), and mating behavior (Young and Wang, 2004). In particular, DA release in the BG is crucial for pair-bond formation during mating (Wang et al., 1999; Aragona et al., 2003). In songbirds, DA affects the motivation to sing (Schroeder and Riters, 2006), and its role in song regulation is likely dependent on social context (Heimovics and Riters, 2008). Moreover, Sasaki et al. (2006) have shown that DA level in Area X is increased in male birds only when they were singing toward a female, a social context associated with stereotyped song production. Our results suggest that higher DA levels in Area X in the presence of a female may be responsible for the decrease in AFP-driven song variability in this social context.

\section{DA in song learning}

BG circuits in general and the AFP in particular are proposed to introduce variability necessary for exploration during motor learning (Graybiel, 2005; Ölveczky et al., 2005). In adult birds, song variability is modulated with social context, and song is less variable when directed to a female than when the same song is sung in isolation (Sossinka and Böhner, 1980). A neural correlate of this behavioral modulation is found in the AFP; firing is reduced and less variable during directed singing in Area $\mathrm{X}$ and LMAN (Hessler and Doupe, 1999; Kao et al., 2008). Immediate early gene expression in Area X is also differentially modulated (Jarvis et al., 1998). Lesion or inactivation of the AFP output nucleus LMAN substantially reduces song variability, suggesting that the AFP regulates both developmental and contextual modulation of song (Kao et al., 2005; Ölveczky et al., 2005).

Recent anatomical and physiological data shed light on a loop circuit linking Area X to DA neurons in the SNc and VTA (Gale et al., 2008; Gale and Perkel, 2010). Through this circuit, song playback activates dopaminergic neurons, which in turn trigger strong DA release in Area X (Gale and Perkel, 2005). Like neurons in the AFP, VTA neurons in adult zebra finches show singingrelated activity that is modulated by social context (Yanagihara and Hessler, 2006), though it is unknown whether the neurons recorded were dopaminergic. Extracellular DA levels in Area X are higher when adult zebra finches sing to a female than when they do not sing or sing alone (Sasaki et al., 2006). Together, these results suggest that the dopaminergic input to Area X could trigger changes in song variability depending on social context. Consistent with these ideas, we have shown that DA decreases the output signal of the AFP through its action on $\mathrm{D}_{1}$ receptors in Area $\mathrm{X}$ and that interfering with $\mathrm{D}_{1}$ receptor transmission in Area $\mathrm{X}$ abolishes social context-dependent changes in song variability. Moreover, we found that LMAN firing evoked by HVC electrical stimulation was shorter in duration when we applied DA in Area $\mathrm{X}$. Such reduced and more precise AFP activity when DA was delivered to Area X resembles AFP song-related activity during directed singing (Hessler and Doupe, 1999; Kao et al., 2008).

In addition to introducing variability, the AFP may provide patterned signals to guide changes in motor output (Kao et al., 2008; Andalman and Fee, 2009). Such signals would most likely come from HVC and be transformed in the AFP, potentially through DA-dependent mechanisms. Indeed, DA modulates the intrinsic excitability of Area X spiny neurons and the strength of their glutamatergic inputs and is necessary for long-term plasticity of these synapses (Ding and Perkel, 2002, 2004; Ding et al., 2003). Here we show that DA also modulates direct excitatory input from HVC to Area X pallidal neurons. Moreover, we show that DA increases spontaneous activity in pallidal neurons and shortens their ISIs. This ISI shortening is likely to modify information transfer through the AFP (Person and Perkel, 2005; Leblois et al., 2009). In addition to the increased spontaneous activity, the reduction in firing variability under DA in Area X pallidal neurons is likely to reduce evoked and/or spontaneous firing in DLM (Leblois et al., 2009), and is most likely responsible for the decrease in song response in LMAN.

\section{DA and reinforcement learning}

Interestingly, reward processing and social interaction processes share common neural substrates (Caldú and Dreher, 2007). In 
particular, DA release in the striatum signals reward prediction error, and may provide a reinforcement signal to the BG (Schultz et al., 1993; Phillips et al., 2003). As a reinforcer, phasic DA delivery could gradually shape motor behavior, thereby inducing a slow shift from motor exploration to the repetition of a successful behavior (exploitation, Sutton and Barto, 1990; Ishii et al., 2002). Here, we highlight another possible role for the DA system in motor learning. According to our results, a change in DA level in the BG might rapidly trigger a switch between exploration and exploitation in learned behaviors. The proposed role of DA in balancing exploration and exploitation by reducing BG output signals is in line with several previous findings. First, DA-regulating genes are responsible for interindividual differences in exploration and exploitation behaviors (Frank et al., 2009). Second, animals treated with drugs enhancing the DA signal such as cocaine or amphetamines induce behavioral stereotypy (Canales and Graybiel, 2000), and a recent study found that cocaine injections leading to stereotyped behavior in rats reduced evoked responses in BG output neurons (Aliane et al., 2009). Finally, differences in movement latency associated with different reward values, possibly reflecting a transition from exploration (when the action outcome is uncertain) to exploitation (when the action outcome is desirable), rely on $\mathrm{D}_{1}$ receptor transmission in the BG in primates (Nakamura and Hikosaka, 2006).

\section{Relation to pathology}

The BG are involved in several movement disorders, including Parkinson's disease (Chesselet and Delfs, 1996). In parkinsonian patients and animal models of the disease DA depletion is associated with increased firing variability in the output neurons of the BG (Boraud et al., 2002). The mechanisms described here and that allow DA to modulate firing variability in BG output may be at least partly responsible for these pathological changes.

\section{Conclusion}

DA acts on $D_{1}$ receptors in Area $X$ to reduce firing variability in pallidal neurons, decreasing AFP output. In social contexts associated with increased DA release in Area X, AFP output is diminished, leading to stereotyped song production driven by the monosynaptic HVC-RA pathway. On the other hand, in social contexts associated with low DA levels in Area X, the AFP output signal is enhanced and leads to strong AFP-driven song variability. Such modulation of the balance between exploration and exploitation may be a critical role of DA in motor learning.

\section{References}

Aliane V, Pérez S, Nieoullon A, Deniau JM, Kemel ML (2009) Cocaineinduced stereotypy is linked to an imbalance between the medial prefrontal and sensorimotor circuits of the basal ganglia. Eur J Neurosci 30:1269-1279.

Andalman AS, Fee MS (2009) A basal ganglia-forebrain circuit in the songbird biases motor output to avoid vocal errors. Proc Natl Acad Sci U S A 106:12518-12523.

Anstrom KK, Miczek KA, Budygin EA (2009) Increased phasic dopamine signaling in the mesolimbic pathway during social defeat in rats. Neuroscience 161:3-12.

Aragona BJ, Wang Z (2009) Dopamine regulation of social choice in a monogamous rodent species. Front Behav Neurosci 3:15.

Aragona BJ, Liu Y, Curtis JT, Stephan FK, Wang Z (2003) A critical role for nucleus accumbens dopamine in partner-preference formation in male prairie voles. J Neurosci 23:3483-3490.

Bagshaw EV, Evans MH (1976) Measurement of current spread from microelectrodes when stimulating within the nervous system. Exp Brain Res 25:391-400.

Baker SN, Gerstein GL (2001) Determination of response latency and its application to normalization of cross-correlation measures. Neural Comput 13:1351-1377.

Barnes TD, Kubota Y, Hu D, Jin DZ, Graybiel AM (2005) Activity of striatal neurons reflects dynamic encoding and recoding of procedural memories. Nature 437:1158-1161.

Bharati IS, Goodson JL (2006) Fos responses of dopamine neurons to sociosexual stimuli in male zebra finches. Neuroscience 143:661-670.

Boraud T, Bezard E, Bioulac B, Gross CE (2002) From single extracellular unit recording in experimental and human Parkinsonism to the development of a functional concept of the role played by the basal ganglia in motor control. Prog Neurobiol 66:265-283.

Bottjer SW (1993) The distribution of tyrosine hydroxylase immunoreactivity in the brains of male and female zebra finches. J Neurobiol 24:51-69.

Bottjer SW, Miesner EA, Arnold AP (1984) Forebrain lesions disrupt development but not maintenance of song in passerine birds. Science 224:901-903.

Brainard MS, Doupe AJ (2002) What songbirds teach us about learning Nature 417:351-358.

Calabresi P, Centonze D, Bernardi G (2000) Electrophysiology of dopamine in normal and denervated striatal neurons. Trends Neurosci 23:S57-S63.

Caldú X, Dreher JC (2007) Hormonal and genetic influences on processing reward and social information. Ann N Y Acad Sci 1118:43-73.

Canales JJ, Graybiel AM (2000) A measure of striatal function predicts motor stereotypy. Nat Neurosci 3:377-383.

Chesselet MF, Delfs JM (1996) Basal ganglia and movement disorders: an update. Trends Neurosci 19:417-422.

Costa RM (2007) Plastic corticostriatal circuits for action learning: what's dopamine got to do with it? Ann N Y Acad Sci 1104:172-191.

Ding L, Perkel DJ (2002) Dopamine modulates excitability of spiny neurons in the avian basal ganglia. J Neurosci 22:5210-5218.

Ding L, Perkel DJ (2004) Long-term potentiation in an avian basal ganglia nucleus essential for vocal learning. J Neurosci 24:488-494.

Ding L, Perkel DJ, Farries MA (2003) Presynaptic depression of glutamatergic synaptic transmission by $\mathrm{D}_{1}$-like dopamine receptor activation in the avian basal ganglia. J Neurosci 23:6086-6095.

Doupe AJ (1997) Song- and order-selective neurons in the songbird anterior forebrain and their emergence during vocal development. J Neurosci 17:1147-1167.

Farries MA, Perkel DJ (2000) Electrophysiological properties of avian basal ganglia neurons recorded in vitro. J Neurophysiol 84:2502-2513.

Farries MA, Ding L, Perkel DJ (2005) Evidence for "direct" and "indirect" pathways through the song system basal ganglia. J Comp Neurol 484:93-104.

Follett KA, Mann MD (1986) Effective stimulation distance for current from macroelectrodes. Exp Neurol 92:75-91.

Frank MJ, Doll BB, Oas-Terpstra J, Moreno F (2009) Prefrontal and striatal dopaminergic genes predict individual differences in exploration and exploitation. Nat Neurosci 12:1062-1068.

Gale SD, Perkel DJ (2005) Properties of dopamine release and uptake in the songbird basal ganglia. J Neurophysiol 93:1871-1879.

Gale SD, Perkel DJ (2010) A basal ganglia pathway drives selective auditory responses in songbird dopaminergic neurons via disinhibition. J Neurosci 30:1027-1037.

Gale SD, Person AL, Perkel DJ (2008) A novel basal ganglia pathway forms a loop linking a vocal learning circuit with its dopaminergic input. J Comp Neurol 508:824-839.

Graybiel AM (2005) The basal ganglia: learning new tricks and loving it. Curr Opin Neurobiol 15:638-644.

Heimovics SA, Riters LV (2008) Evidence that dopamine within motivation and song control brain regions regulates birdsong context-dependently. Physiol Behav 95:258-266.

Hessler NA, Doupe AJ (1999) Social context modulates singing-related neural activity in the songbird forebrain. Nat Neurosci 2:209-211.

Hikosaka O, Nakamura K, Sakai K, Nakahara H (2002) Central mechanisms of motor skill learning. Curr Opin Neurobiol 12:217-222.

Ishii S, Yoshida W, Yoshimoto J (2002) Control of exploitation-exploration meta-parameter in reinforcement learning. Neural Netw 15:665-687.

Jarvis ED, Scharff C, Grossman MR, Ramos JA, Nottebohm F (1998) For whom the bird sings: context-dependent gene expression. Neuron 21:775-788.

Kao MH, Brainard MS (2006) Lesions of an avian basal ganglia circuit pre- 
vent context-dependent changes to song variability. J Neurophysiol 96:1441-1455.

Kao MH, Doupe AJ, Brainard MS (2005) Contributions of an avian basal ganglia-forebrain circuit to real-time modulation of song. Nature 433:638-643.

Kao MH, Wright BD, Doupe AJ (2008) Neurons in a forebrain nucleus required for vocal plasticity rapidly switch between precise firing and variable bursting depending on social context. J Neurosci 28:1323213247.

Kiyatkin EA, Rebec GV (1996) Dopaminergic modulation of glutamateinduced excitations of neurons in the neostriatum and nucleus accumbens of awake, unrestrained rats. J Neurophysiol 75:142-153.

Kiyatkin EA, Rebec GV (1999) Striatal neuronal activity and responsiveness to dopamine and glutamate after selective blockade of $\mathrm{D}_{1}$ and $\mathrm{D}_{2}$ dopamine receptors in freely moving rats. J Neurosci 19:3594-3609.

Kliem MA, Maidment NT, Ackerson LC, Chen S, Smith Y, Wichmann T (2007) Activation of nigral and pallidal dopamine $D_{1}$-like receptors modulates basal ganglia outflow in monkeys. J Neurophysiol 98:14891500.

Kojima S, Doupe AJ (2009) Activity propagation in an avian basal gangliathalamocortical circuit essential for vocal learning. J Neurosci 29:47824793.

Leblois A, Bodor AL, Person AL, Perkel DJ (2009) Millisecond timescale disinhibition mediates fast information transmission through an avian basal ganglia loop. J Neurosci 29:15420-15433.

Lewis JW, Ryan SM, Arnold AP, Butcher LL (1981) Evidence for a catecholaminergic projection to area $\mathrm{X}$ in the zebra finch. J Comp Neurol 196:347-354.

MacDougall-Shackleton SA, Hulse SH, Ball GF (1998) Neural correlates of singing behavior in male zebra finches (Taeniopygia guttata). J Neurobiol 36:421-430.

Meitzen J, Moore IT, Lent K, Brenowitz EA, Perkel DJ (2007) Steroid hormones act transsynaptically within the forebrain to regulate neuronal phenotype and song stereotypy. J Neurosci 27:12045-12057.

Miczek KA, Gold LH (1983) Ethological analysis of amphetamine action on social behavior in squirrel monkeys (Saimiri sciureus). Prog Clin Biol Res 131:137-155.

Montague PR, Dayan P, Sejnowski TJ (1996) A framework for mesencephalic dopamine systems based on predictive Hebbian learning. J Neurosci 16:1936-1947.

Nakamura K, Hikosaka O (2006) Role of dopamine in the primate caudate nucleus in reward modulation of saccades. J Neurosci 26:5360-5369.

Nicola SM, Surmeier J, Malenka RC (2000) Dopaminergic modulation of neuronal excitability in the striatum and nucleus accumbens. Annu Rev Neurosci 23:185-215.

Nordeen KW, Nordeen EJ (1997) Anatomical and synaptic substrates for avian song learning. J Neurobiol 33:532-548.

Ölveczky BP, Andalman AS, Fee MS (2005) Vocal experimentation in the juvenile songbird requires a basal ganglia circuit. PLoS Biol 3:e153.

Person AL, Perkel DJ (2005) Unitary IPSPs drive precise thalamic spiking in a circuit required for learning. Neuron 46:129-140.

Person AL, Perkel DJ (2007) Pallidal neuron activity increases during sensory relay through thalamus in a songbird circuit essential for learning. J Neurosci 27:8687-8698.

Phillips PE, Stuber GD, Heien ML, Wightman RM, Carelli RM (2003) Sub- second dopamine release promotes cocaine seeking. Nature 422:614618.

Puglisi-Allegra S, Cabib S (1997) Psychopharmacology of dopamine: the contribution of comparative studies in inbred strains of mice. Prog Neurobiol 51:637-661.

Ranck JB Jr (1975) Which elements are excited in electrical stimulation of mammalian central nervous system: a review. Brain Res 98:417-440.

Rolls ET, Thorpe SJ, Boytim M, Szabo I, Perrett DI (1984) Responses of striatal neurons in the behaving monkey. 3. Effects of iontophoretically applied dopamine on normal responsiveness. Neuroscience 12:12011212.

Sakata JT, Brainard MS (2008) Online contributions of auditory feedback to neural activity in avian song control circuitry. J Neurosci 28:1137811390.

Salamone JD, Correa M, Mingote SM, Weber SM (2005) Beyond the reward hypothesis: alternative functions of nucleus accumbens dopamine. Curr Opin Pharmacol 5:34-41.

Sasaki A, Sotnikova TD, Gainetdinov RR, Jarvis ED (2006) Social contextdependent singing-regulated dopamine. J Neurosci 26:9010-9014.

Scharff C, Nottebohm F (1991) A comparative study of the behavioral deficits following lesions of various parts of the zebra finch song system: implications for vocal learning. J Neurosci 11:2896-2913.

Schroeder MB, Riters LV (2006) Pharmacological manipulations of dopamine and opioids have differential effects on sexually motivated song in male European starlings. Physiol Behav 88:575-584.

Schultz W, Apicella P, Ljungberg T (1993) Responses of monkey dopamine neurons to reward and conditioned stimuli during successive steps of learning a delayed response task. J Neurosci 13:900-913.

Smith Y, Villalba R (2008) Striatal and extrastriatal dopamine in the basal ganglia: an overview of its anatomical organization in normal and Parkinsonian brains. Mov Disord 23 [Suppl 3]:S534-S547.

Solis MM, Doupe AJ (1997) Anterior forebrain neurons develop selectivity by an intermediate stage of birdsong learning. J Neurosci 17:6447-6462.

Sossinka R, Böhner J (1980) Song types in the zebra finch Poephila guttata castanotis. Z Tierpsychol 53:123-132.

Sutton RS, Barto AG (1990) Time derivative models of Pavlovian reinforcement. In: Learning and computational neuroscience: foundations of adaptive networks (Gabriel MR, Moore JW, eds), pp 497-537. Cambridge, MA: MIT.

Tehovnik EJ, Tolias AS, Sultan F, Slocum WM, Logothetis NK (2006) Direct and indirect activation of cortical neurons by electrical microstimulation. J Neurophysiol 96:512-521.

Wang Z, Yu G, Cascio C, Liu Y, Gingrich B, Insel TR (1999) Dopamine D2 receptor-mediated regulation of partner preferences in female prairie voles (Microtus ochrogaster): a mechanism for pair bonding? Behav Neurosci 113:602-611.

Wise RA (2004) Dopamine, learning and motivation. Nat Rev Neurosci 5:483-494.

Yanagihara S, Hessler NA (2006) Modulation of singing-related activity in the songbird ventral tegmental area by social context. Eur J Neurosci 24:3619-3627.

Young LJ, Wang Z (2004) The neurobiology of pair bonding. Nat Neurosci 7:1048-1054.

Zhou FW, Jin Y, Matta SG, Xu M, Zhou FM (2009) An ultra-short dopamine pathway regulates basal ganglia output. J Neurosci 29:10424-10435. 